\title{
Dumulmycin, an Antitubercular Bicyclic Macrolide from a Riverine Sediment-Derived Streptomyces sp.
}

Joon Soo An, ${ }^{\dagger}$ Bora Shin, ${ }^{\dagger}$ Tae Ho Kim,,${ }^{\S}$ Sunghoon Hwang,${ }^{\dagger}$ Yern-Hyerk Shin, ${ }^{\dagger}$ Jinsheng Cui,${ }^{\dagger}$ Young Eun Du, ${ }^{\dagger}$ Jungwoo Yi, ${ }^{\dagger}$ Sang-Jip Nam, ${ }^{\star}$ Suckchang Hong, ${ }^{\Delta}$ Jongheon Shin,${ }^{\dagger}$ Jichan Jang, ${ }^{\S}$ Yeo Joon Yoon, ${ }^{\dagger}$ Dong-Chan $\mathrm{Oh}^{*}{ }^{\dagger}$

'Natural Products Research Institute, College of Pharmacy, Seoul National University, Seoul 08826, Republic of Korea

${ }^{\S}$ Molecular Mechanism of Antibiotics, Division of Life Science, Division of Bio \& Medical Big Data Department (BK4 Program), Research Institute of Life Science, Gyeongsang National University, Jinju, Gyeongnam 52828, Republic of Korea

Department of Chemistry and Nanoscience, Ewha Womans University, Seoul 03760, Republic of Korea ${ }^{\Delta}$ Research Institute of Pharmaceutical Sciences, College of Pharmacy, Seoul National University, Seoul 08826, Republic of Korea

\section{Correspondence to:}

Prof. Dong-Chan Oh

Natural Products Research Institute,

College of Pharmacy,

Seoul National University, 1 Gwanak-ro, Gwanak-gu,

Seoul 08826, Republic of Korea

TEL: 82-2-880-2491; FAX: 82-2-762-8322; E-mail: dongchanoh@ snu.ac.kr 
S3 General experimental procedures

S3 Isolation of the bacterial strain

S3 Cultivation and extraction

S3 Isolation

S4 Table S1. ${ }^{1} \mathrm{H}$ and ${ }^{13} \mathrm{C}$ NMR data for dumulmycin (1)

S5 Figure S1. ${ }^{1} \mathrm{H}$ NMR spectrum of dumulmycin (1) at $850 \mathrm{MHz}$ in DMSO- $d_{6}$.

Figure S2. ${ }^{13} \mathrm{C}$ NMR spectrum of dumulmycin (1) at $200 \mathrm{MHz}$ in DMSO- $d_{6}$.

S6 Figure S3. COSY NMR spectrum of dumulmycin (1) at $800 \mathrm{MHz}$ in DMSO- $d_{6}$

Figure S4. HSQC NMR spectrum of dumulmycin (1) at $800 \mathrm{MHz}$ in DMSO- $d_{6}$.

S7 Figure S5. HMBC NMR spectrum of dumulmycin (1) at $800 \mathrm{MHz}$ in DMSO- $d_{6}$.

Figure S6. ROESY NMR spectrum of dumulmycin (1) at $800 \mathrm{MHz}$ in DMSO- $d_{6}$.

S8 Figure S7. HETLOC NMR spectrum of dumulmycin (1) at $800 \mathrm{MHz}$ in DMSO- $d_{6}$.

Figure S8. HECADE NMR spectrum of dumulmycin (1) at $800 \mathrm{MHz}$ in DMSO- $d_{6}$.

S9 Figure S9. e.COSY NMR spectrum of dumulmycin (1) at $800 \mathrm{MHz}$ in DMSO- $d_{6}$.

Figure S10. HR-ESI-MS data of dumulmycin (1).

S10 Preparing MTPA esters of dumulmycin (1)

S11 Figure S11. HR-ESI-MS data of $(S)$-MTPA ester product (1a).

Figure S12. HR-ESI-MS data of $(R)$-MTPA ester product (1b).

S12 Figure S13. ${ }^{1} \mathrm{H}$ NMR spectrum of $(S)$-MTPA ester (1a) of 1 at $800 \mathrm{MHz}$ in DMSO- $d_{6}$.

Figure S14. COSY NMR spectrum of (S)-MTPA ester (1a) of 1 at $800 \mathrm{MHz}$ in DMSO- $d_{6}$.

S13 Figure S15. ${ }^{1} \mathrm{H}$ NMR spectrum of $(R)$-MTPA ester (1b) of 1 at $850 \mathrm{MHz}$ in DMSO- $d_{6}$. Figure S16. COSY NMR spectrum of (R)-MTPA ester (1b) of 1 at $850 \mathrm{MHz}$ in DMSO- $d_{6}$.

S14 Conformational search and DP4 analysis of dumulmycin (1)

Figure S17. Result of DP4 calculation from the simulated models of two possible diastereomers.

S16 Table S2. The major conformers of diastereomers $1 \mathrm{c}$ and $\mathbf{1 d}$ of dumulmycin (1) identified by conformational searches in MMFF94 force field using Macromodel.

S16-S17 Table S3. Experimental (Exp.) and calculated (Cal.) chemical shift values (CS, $\delta$ ) of diastereomers 1c and $\mathbf{1 d}$ of dumulmycin (1).

\section{S18 Genome Sequencing of Streptomyces sp. DM28}

S19-S21 Table S4. Putative functions of genes in the dumulmycin (1) biosynthetic gene clusters.

S22-S23 Figure S18. Multiple sequence alignment of the amino acids of catalytic domains.

S24 Figure S19. (a) Plausible post-modular modification of dumulmycin (1) and energy-minimized model of (b) divinyl ketone intermediate and (c) enol intermediate at B3-LYP/DFT model.

S25 MIC determination using resazurin microtiter assay

Figure S20. Determination of MIC value of dumulmycin (1) for Mycobacterium tuberculosis by resazurin microtiter assay (REMA).

S26 Figure S21. $J$-based configuration analysis of dumulmycin (1) at (a) C-21 and C22, (b) C-20 and C-21, and (c) C-19 and C-20.

S27 Figure S22. Predicted structure of modules 5-7 by TransATor.

S28 References 


\section{General experimental procedures}

Optical rotation values were measured using a JASCO P-2000 polarimeter (sodium light source, JASCO, Easton, PA, USA) with a $1 \mathrm{~cm}$ cell at $25^{\circ} \mathrm{C}$. UV spectroscopic data was acquired using a Chirascan-Plus Applied Photophysics spectrophotometer. IR spectra were collected using a Thermo Scientific Nicolet iS10 FT-IR spectrometer (Thermo Fisher Scientific, Waltham, MA, USA). ${ }^{1} \mathrm{H},{ }^{13} \mathrm{C}$, and $2 \mathrm{D}$ nuclear magnetic resonance (NMR) spectra were recorded on a Bruker Avance $800 \mathrm{MHz}$ spectrometer (Bruker, Billerica, MA, USA) at the Research Institute of Pharmaceutical Sciences at Seoul National University and a Bruker Advance III $850 \mathrm{MHz}$ spectrometer at the National Center for Inter-University Research Facilities (NCIRF). Low-resolution electrospray ionization (ESI) LC/MS data was acquired using an Agilent Technologies 6130 quadrupole mass spectrometer (Agilent Technologies, Santa Clara, CA, USA) coupled with an Agilent Technologies 1200 series high-performance liquid chromatography (HPLC) instrument using a reversed-phase $\mathrm{C}_{18}(2)$ column (Phenomenex Luna, $100 \times 4.6 \mathrm{~mm}, 5 \mu \mathrm{m}$ ). High-resolution electrospray ionization (HR-ESI) mass spectroscopic data was recorded using a Thermo Scientific Q high-resolution mass spectrometer at the National Instrumentation Center for Environmental Management (NICEM) at Seoul National University.

\section{Isolation of the bacterial strain}

A sandy sediment sample was collected at Dumulmeori, Yangpyeong-gun, Gyeonggi-do, Republic of Korea in a $40 \mathrm{~mL}$ sterilized conical tube in February 2020. The sample $(4 \mathrm{~g})$ was diluted and vortexed in $30 \mathrm{~mL}$ of sterilized deionized water. The mixture was spread onto Actinomycete Isolation Agar, A4 medium (1 L distilled water, $18 \mathrm{~g}$ agar, and $100 \mathrm{mg} / \mathrm{L}$ cycloheximide), ISP2 medium $(1 \mathrm{~L}$ distilled water, $4 \mathrm{~g}$ yeast, $10 \mathrm{~g}$ malt, $4 \mathrm{~g}$ glucose, $18 \mathrm{~g}$ agar, and $100 \mathrm{mg} / \mathrm{L}$ cycloheximide), and $\mathrm{A} 1 \mathrm{medium}$ (1 L distilled water, $10 \mathrm{~g}$ starch, $4 \mathrm{~g}$ yeast, 2 g peptone, and $100 \mathrm{mg} / \mathrm{L}$ cycloheximide). The bacterial strain DM28 was isolated from A1 medium as a single strain. It is phylogenetically closest to Streptomyces marokkonensis based on the $16 \mathrm{~S}$ rDNA sequence $(96.08 \%$ identity, GenBank accession number MW237665). The strain DM28 also showed the second most homology (95.92\%) to Streptomyces parvulus NBRC 13193 (GenBank accession number NR_041119) originated from Pearl River Delta at Macau. ${ }^{1}$

\section{Cultivation and extraction}

The DM28 strain was cultured in $50 \mathrm{~mL}$ of DSY medium $(1 \mathrm{~L}$ distilled water, $10 \mathrm{~g}$ dextrin, $4 \mathrm{~g}$ soytone, $1 \mathrm{~g}$ yeast, and $0.25 \mathrm{~g} \mathrm{NaCl}$ ) in a $125-\mathrm{mL}$ Erlenmeyer flask. After cultivation for 5 days on a rotary shaker at 200 $\mathrm{rpm}$ at $30^{\circ} \mathrm{C}, 5 \mathrm{~mL}$ of the culture was inoculated in $250 \mathrm{~mL}$ of DSY medium in a $500-\mathrm{mL}$ Erlenmeyer baffled flask. After 4 days of incubation, $20 \mathrm{~mL}$ of the culture was transferred into $1.5 \mathrm{~L}$ of DSY medium in 2.5-L Ultra Yield flasks $\left(30 \mathrm{ea} \times 1.5 \mathrm{~L}\right.$, total volume $45 \mathrm{~L}$ ) for 4 days at $170 \mathrm{rpm}$ at $30^{\circ} \mathrm{C}$. A total of $45 \mathrm{~L}$ of the DM28 whole culture was extracted using $60 \mathrm{~L}$ of ethyl acetate (EtOAc). The EtOAc and water layers were separated. The remaining water in the EtOAc layer was removed using anhydrous $\mathrm{Na}_{2} \mathrm{SO}_{4}$. The EtOAc extract was concentrated in vacuo to yield $25 \mathrm{~g}$ of the organic material. The extraction process was carried out with minimal exposure to light.

\section{Isolation}

The crude extract fractionated over a $\mathrm{C}_{18}$ reversed-phase open column $(34 \times 150 \mathrm{~mm})$, using a step gradient solvent system $\left(20,40,60,80\right.$, and $100 \% \mathrm{MeOH}_{-} \mathrm{H}_{2} \mathrm{O}, 400 \mathrm{~mL}$ each). Dumulmycin (1) was detected in the $60 \%$ $\mathrm{MeOH}-\mathrm{H}_{2} \mathrm{O}$ fraction. The $60 \% \mathrm{MeOH}-\mathrm{H}_{2} \mathrm{O}$ fraction was injected into a semi-preparative reversed-phase HPLC (Kromasil $100-5-\mathrm{C}_{18}, 10 \times 250 \mathrm{~mm}, 5 \mu \mathrm{m}$, acetonitrile/water $=30 / 70$ to $60 / 40,30 \mathrm{~min}$, flow rate $=2.0 \mathrm{~mL} / \mathrm{min}$, $1=230 \mathrm{~nm}$ ) $\mathrm{t}_{\mathrm{R}}=23.0 \mathrm{~min}$. Compound 1 was further purified reversed-phase HPLC (Kromasil 100-5- $\mathrm{C}_{18}, 10 \times$ $250 \mathrm{~mm}, 5 \mu \mathrm{m}$, acetonitrile $/$ water $=35 / 65$, flow rate $=2.0 \mathrm{~mL} / \mathrm{min}, 1=230 \mathrm{~nm}) \mathrm{t}_{\mathrm{R}}=40.0 \mathrm{~min}$. It was then extracted using EtOAc. Under the second HPLC conditions, $1(10 \mathrm{mg})$ was eluted at $40 \mathrm{~min}$. The strong IR absorption at $1705 \mathrm{~cm}^{-1}$ indicated the existence of a carbonyl group whereas the shoulder peak at $1656 \mathrm{~cm}^{-1}$ was deduced to be originated from a conjugated double bond system. ${ }^{2}$

Dumulmycin (1): yellowish oil; $[\alpha]_{\mathrm{D}}{ }^{25}-3.4(c 0.1, \mathrm{MeOH})$; UV (MeOH) $\lambda_{\max }(\log \varepsilon) 246(2.59) \mathrm{nm}$; IR (neat) $v_{\max } 3399,1705,1656,1402 \mathrm{~cm}^{-1}$; ${ }^{1} \mathrm{H}$ and ${ }^{13} \mathrm{C}$ NMR $\left(800 \mathrm{MHz}\right.$ and $850 \mathrm{MHz}$, DMSO- $d_{6}$ ), see Table S1; HRMS (ESI) $m / z$ : $[\mathrm{M}+\mathrm{Na}]^{+}$Calcd for $\mathrm{C}_{33} \mathrm{H}_{48} \mathrm{O}_{8} \mathrm{Na}, 595.3241$; Found 595.3243. 
Table S1. ${ }^{1} \mathrm{H}$ and ${ }^{13} \mathrm{C}$ NMR data for dumulmycin (1)

\begin{tabular}{|c|c|c|}
\hline position & $\delta_{\mathrm{C}}$, type & $\begin{array}{l}\text { Dumulmycin }(\mathbf{1})^{a} \\
\delta_{\mathrm{H}, \text { mult }}(J \text { in } \mathrm{Hz})\end{array}$ \\
\hline 1 & $170.8, \mathrm{C}$ & \\
\hline $2 \mathrm{a}$ & $33.2, \mathrm{CH}_{2}$ & $3.09, \mathrm{~m}$ \\
\hline $2 b$ & & $2.95, \mathrm{dd}(16.0,8.0)$ \\
\hline 3 & $115.8, \mathrm{CH}$ & $5.48, \mathrm{dd}(8.0,8.0)$ \\
\hline 4 & $141.3, \mathrm{C}$ & \\
\hline 5 & $72.2, \mathrm{CH}$ & $4.81, \mathrm{dd}(8.4,3.0)$ \\
\hline 6 & 134.0, $\mathrm{CH}$ & $5.43, \mathrm{~d}(8.4)$ \\
\hline 7 & $131.6, \mathrm{C}$ & \\
\hline 8 & $136.2, \mathrm{CH}$ & $6.18, \mathrm{~d}(15.0)$ \\
\hline 9 & $129.5, \mathrm{CH}$ & $5.31, \mathrm{dd}(15.0,9.5)$ \\
\hline 10 & $50.3, \mathrm{CH}$ & $2.83, \mathrm{~d}(9.5)$ \\
\hline 11 & $144.5, \mathrm{C}$ & \\
\hline 12 & 148.5, C & \\
\hline 13 & 201.4, C & \\
\hline 14 & $49.4, \mathrm{CH}$ & $3.08, \mathrm{~m}$ \\
\hline 15 & $126.0, \mathrm{CH}$ & $5.08, \mathrm{dd}(10.0,10.0)$ \\
\hline 16 & 137.9, $\mathrm{CH}$ & $5.55, \mathrm{dd}(10.0,7.7)$ \\
\hline 17 & $65.0, \mathrm{CH}$ & $4.23, \mathrm{~m}$ \\
\hline $18 \mathrm{a}$ & $43.5, \mathrm{CH}_{2}$ & $1.50,{ }^{b} \mathrm{~m}$ \\
\hline $18 b$ & & 1.36 , ddd $(14.0,6.7,1.8)$ \\
\hline 19 & $67.3, \mathrm{CH}$ & $3.78, \mathrm{~m}$ \\
\hline 20 & $37.8, \mathrm{CH}$ & $1.50,{ }^{b} \mathrm{~m}$ \\
\hline 21 & 79.3, CH & $4.77, \mathrm{dd}(9.3,2.5)$ \\
\hline 22 & $32.3, \mathrm{CH}$ & $1.82, \mathrm{~m}$ \\
\hline $23 \mathrm{a}$ & $23.3, \mathrm{CH}_{2}$ & $1.65, \mathrm{~m}$ \\
\hline $23 b$ & & $1.17, \mathrm{~m}$ \\
\hline $24 \mathrm{a}$ & $39.9, \mathrm{CH}_{2}$ & 2.43, ddd $(16.5,9.4,5.4)$ \\
\hline $24 b$ & & 2.34, ddd $(16.5,9.2,6.5)$ \\
\hline 25 & $210.6, \mathrm{C}$ & \\
\hline 26 & 43.7, $\mathrm{CH}_{2}$ & $2.38, \mathrm{t}(7.3)$ \\
\hline 27 & $16.7, \mathrm{CH}_{2}$ & $1.45, \mathrm{~m}$ \\
\hline 28 & 13.6, $\mathrm{CH}_{3}$ & $0.81, \mathrm{t}(7.3)$ \\
\hline 29 & $11.7, \mathrm{CH}_{3}$ & $1.57, \mathrm{~s}$ \\
\hline 30 & $12.8, \mathrm{CH}_{3}$ & $1.75, \mathrm{~s}$ \\
\hline 31 & $12.4, \mathrm{CH}_{3}$ & $1.74, \mathrm{~s}$ \\
\hline 32 & $8.7, \mathrm{CH}_{3}$ & $0.52, \mathrm{~d}(5.2)$ \\
\hline 33 & $16.6, \mathrm{CH}_{3}$ & $0.75, \mathrm{~d}(6.6)$ \\
\hline $5-\mathrm{OH}$ & & $4.95, \mathrm{~d}(3.0)$ \\
\hline $12-\mathrm{OH}$ & & $9.15, \mathrm{~s}$ \\
\hline 17-OH & & $4.86, \mathrm{~d}(4.3)$ \\
\hline 19-OH & 5 & $4.13, \mathrm{~d}(4.6)$ \\
\hline
\end{tabular}


Figure S1. ${ }^{1} \mathrm{H}$ NMR spectrum of dumulmycin (1) at $850 \mathrm{MHz}$ in DMSO-d $d_{6}$.

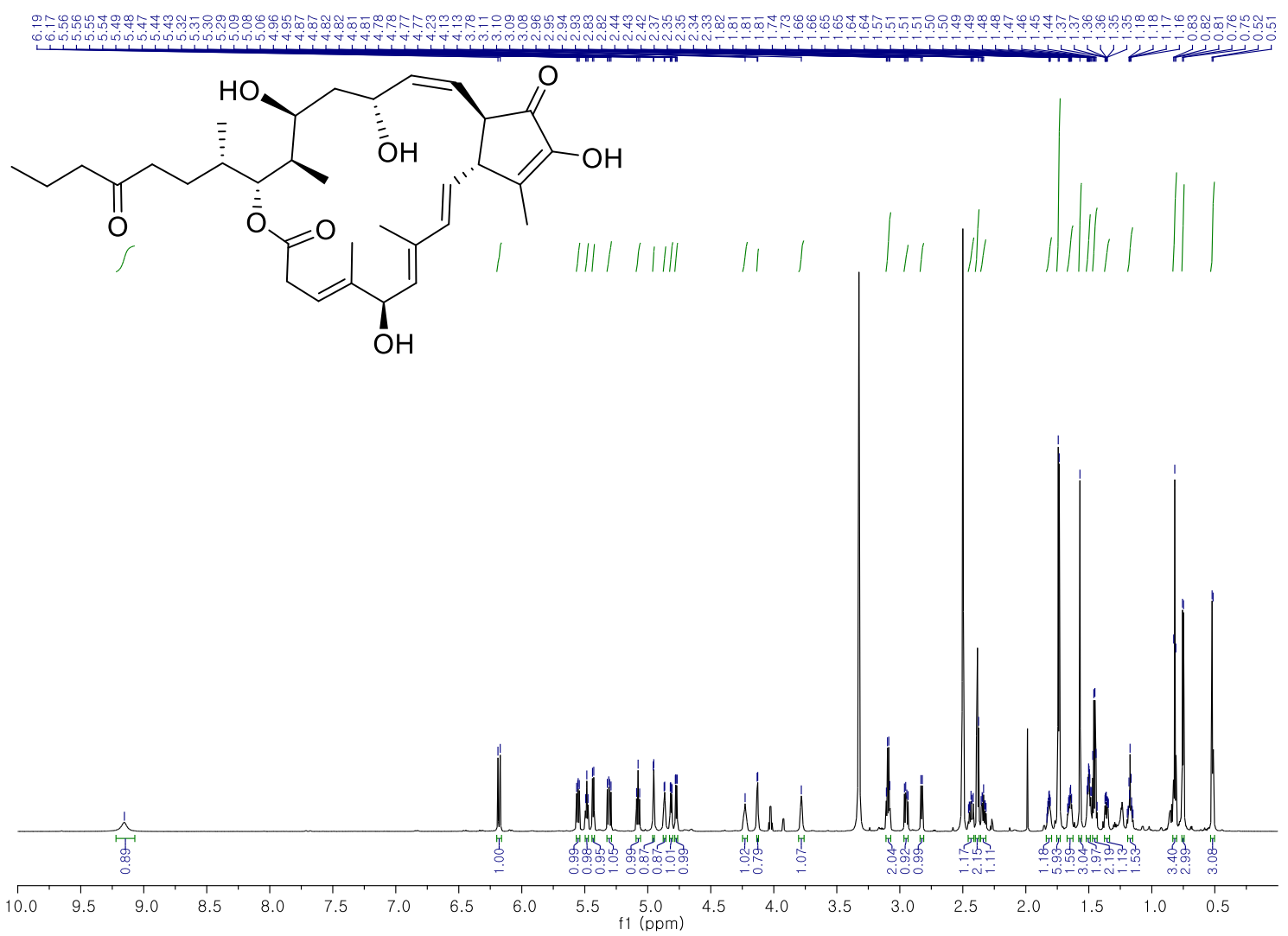

Figure S2. ${ }^{13} \mathrm{C}$ NMR spectrum of dumulmycin (1) at $200 \mathrm{MHz}$ in DMSO- $d_{6}$.

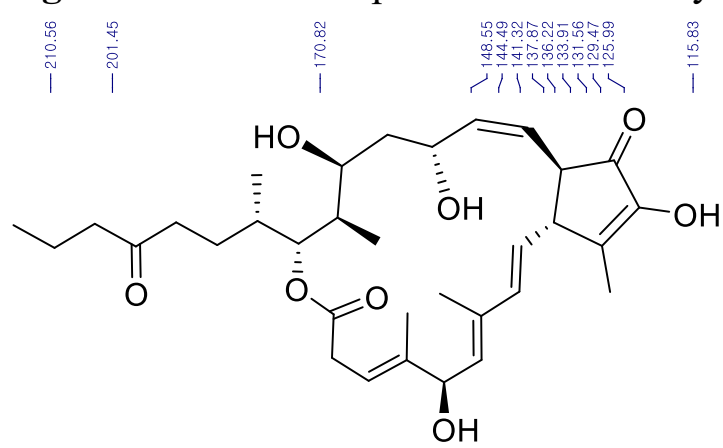

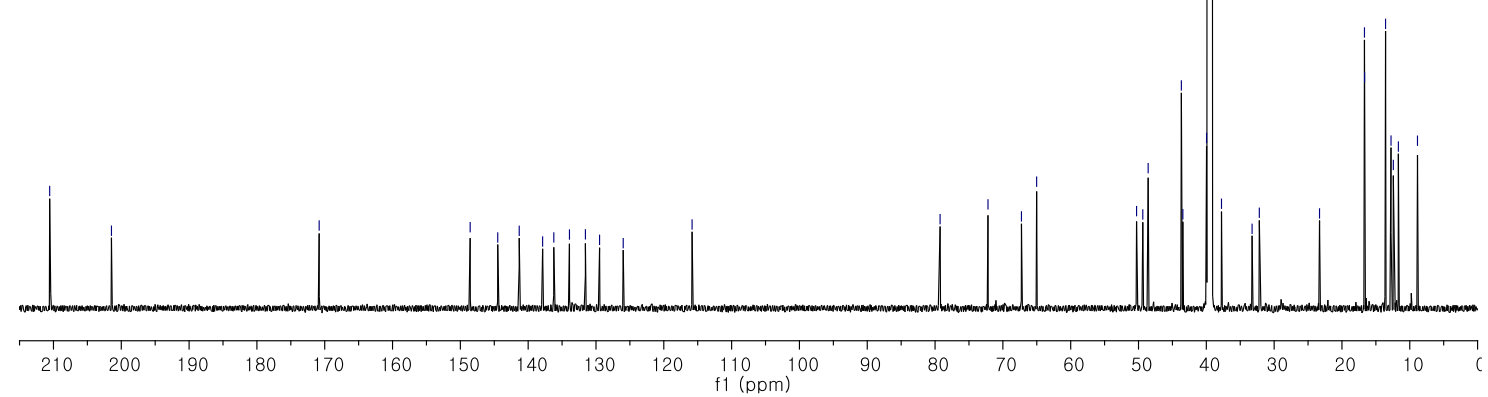


Figure S3. COSY NMR spectrum of dumulmycin (1) at $800 \mathrm{MHz}$ in DMSO- $d_{6}$.

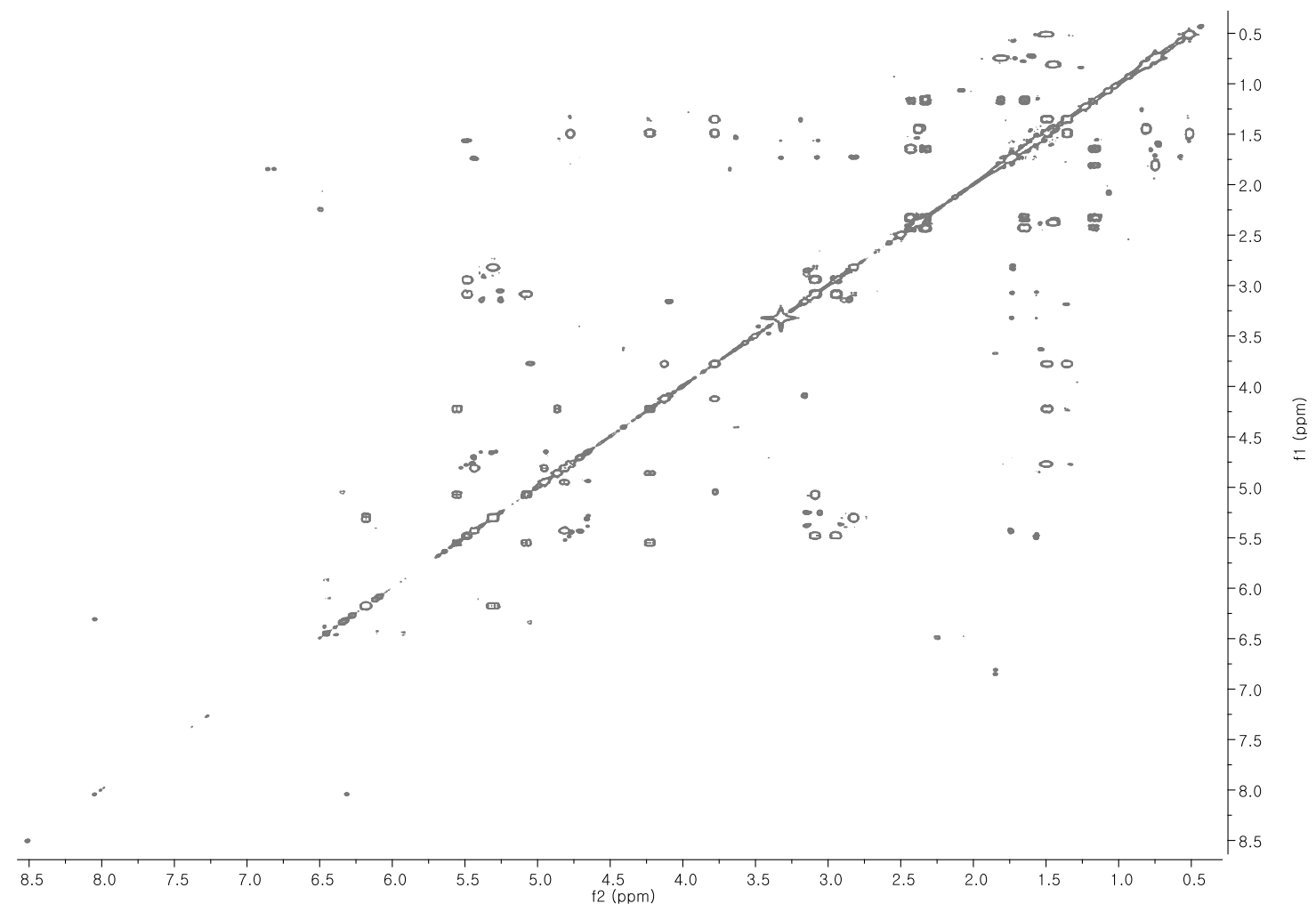

Figure S4. HSQC NMR spectrum of dumulmycin (1) at $800 \mathrm{MHz}$ in DMSO- $d_{6}$.

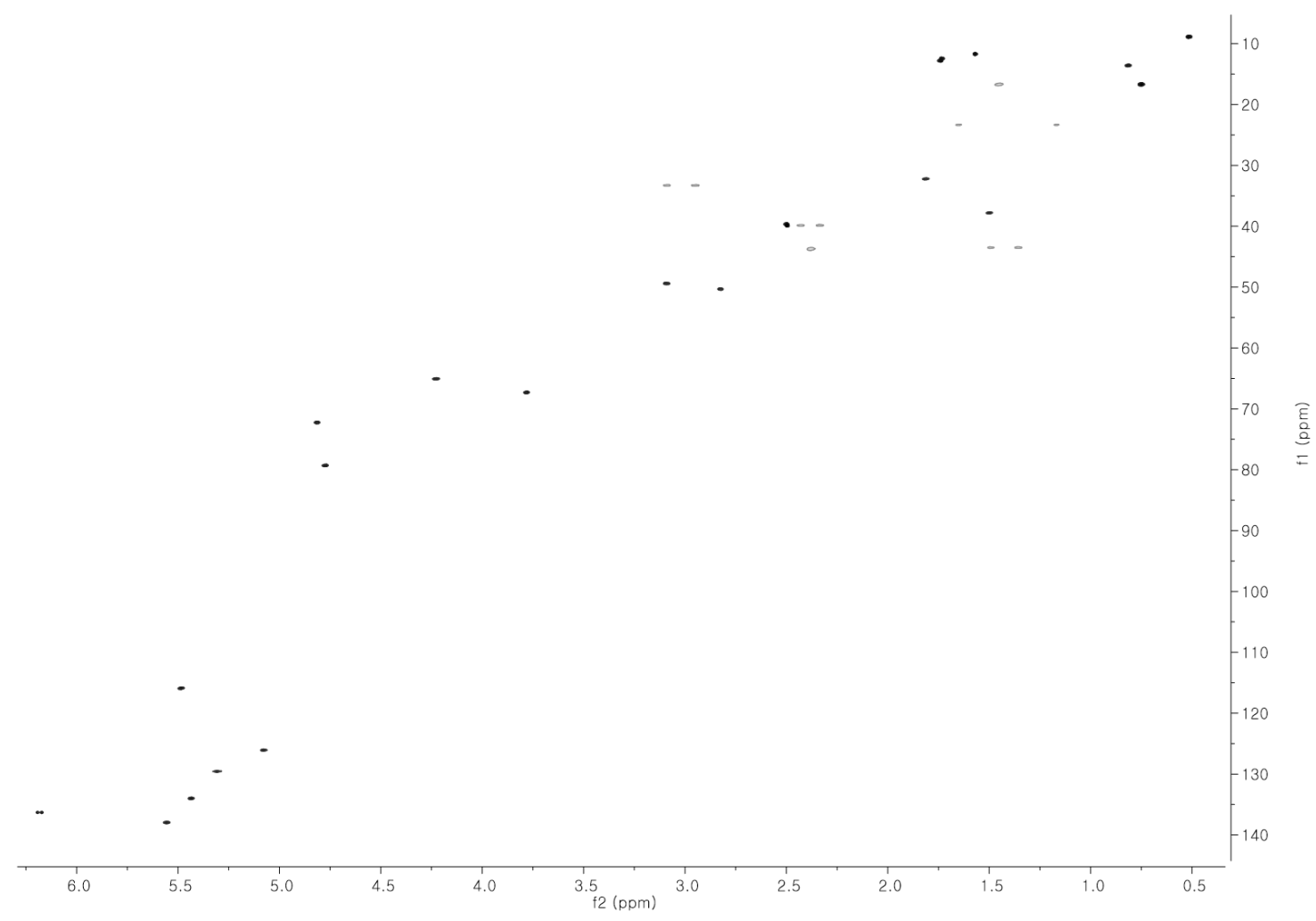


Figure S5. HMBC NMR spectrum of dumulmycin (1) at $800 \mathrm{MHz}$ in DMSO- $d_{6}$.

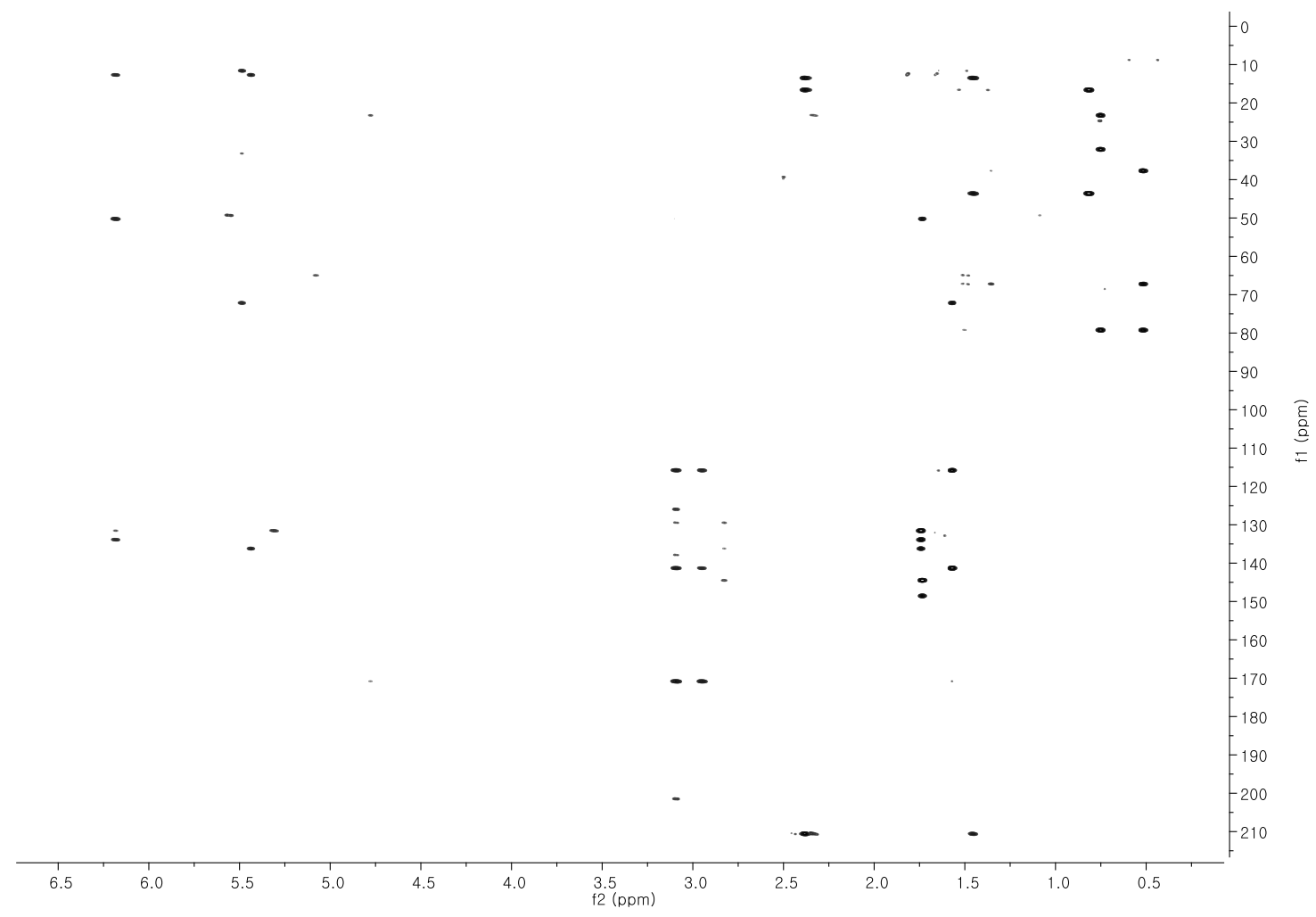

Figure S6. ROESY NMR spectrum of dumulmycin (1) at $800 \mathrm{MHz}$ in DMSO- $d_{6}$.

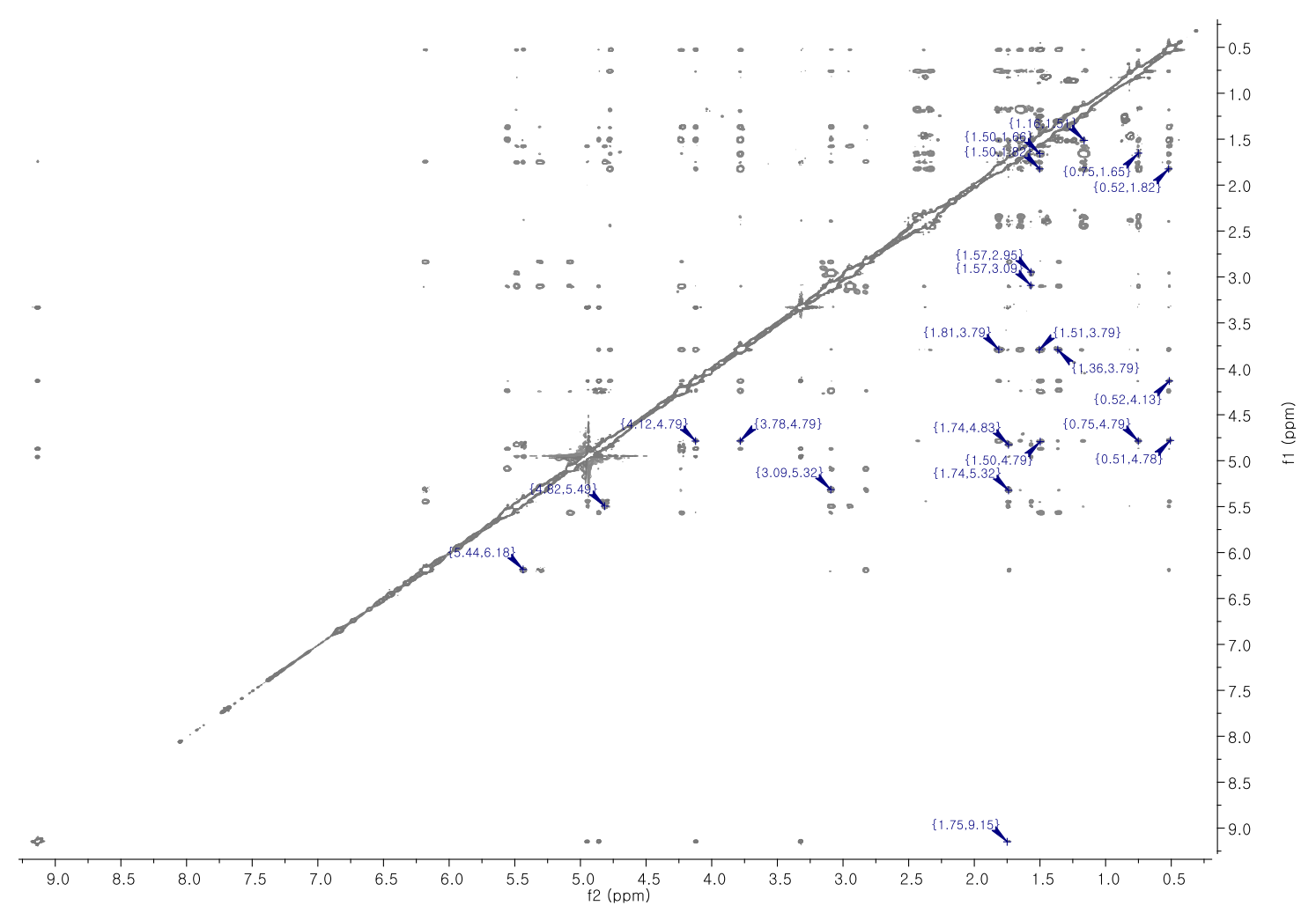


Figure S7. HETLOC NMR spectrum of dumulmycin (1) at $800 \mathrm{MHz}$ in DMSO- $d_{6}$.

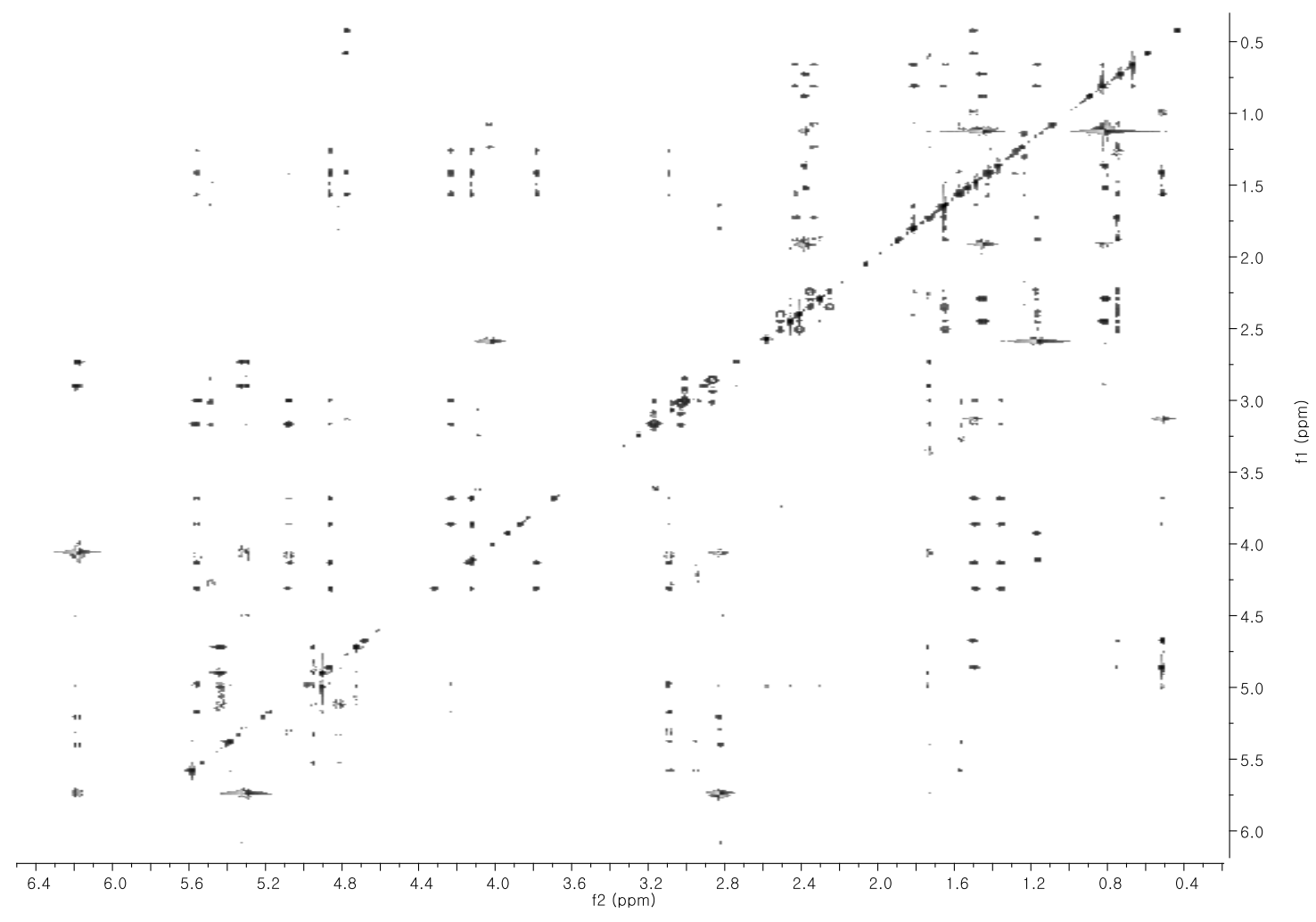

Figure S8. HECADE NMR spectrum of dumulmycin (1) at $800 \mathrm{MHz}$ in DMSO- $d_{6}$.

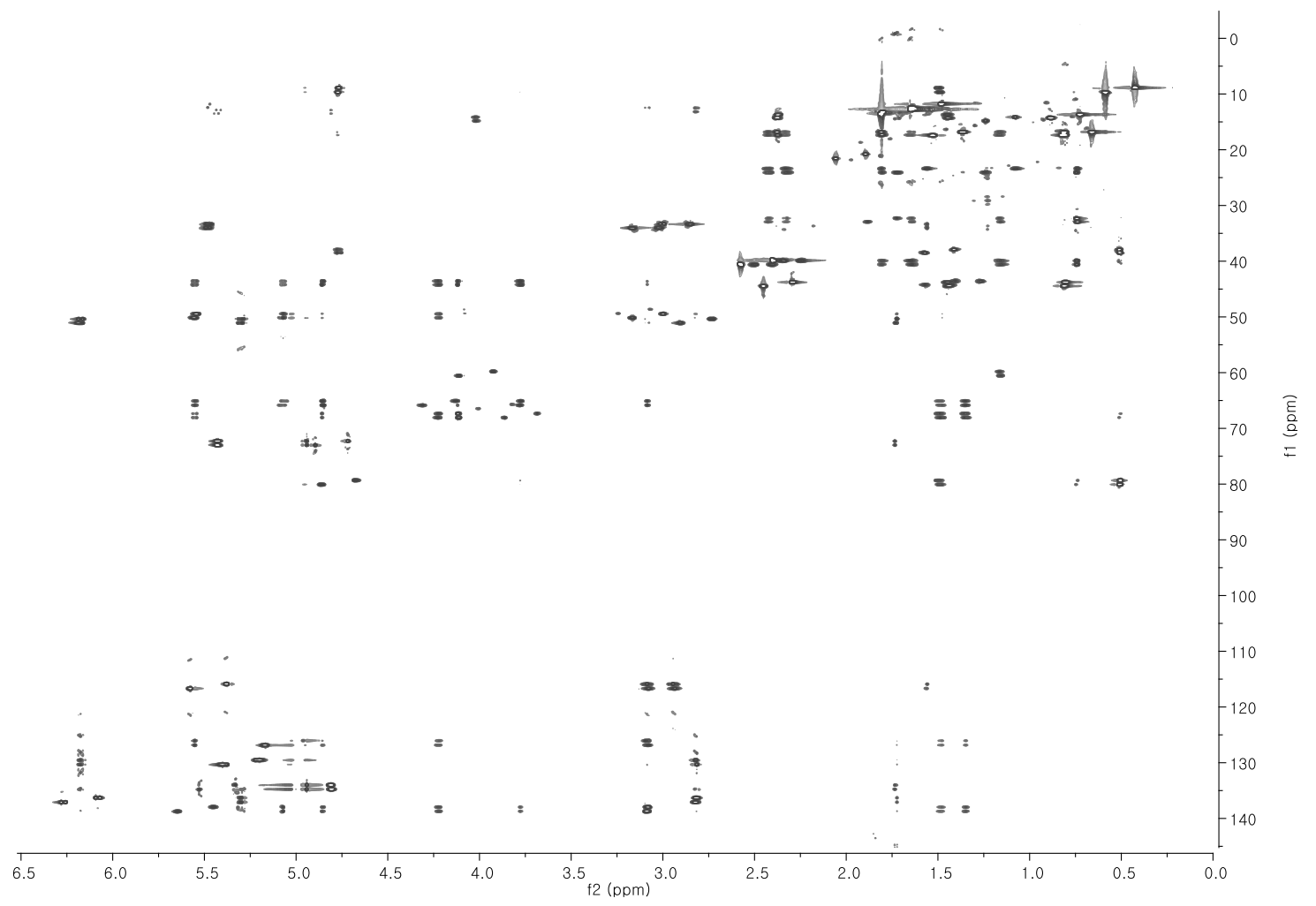


Figure S9. e.COSY NMR spectrum of dumulmycin (1) at $850 \mathrm{MHz}$ in DMSO- $d_{6}$.

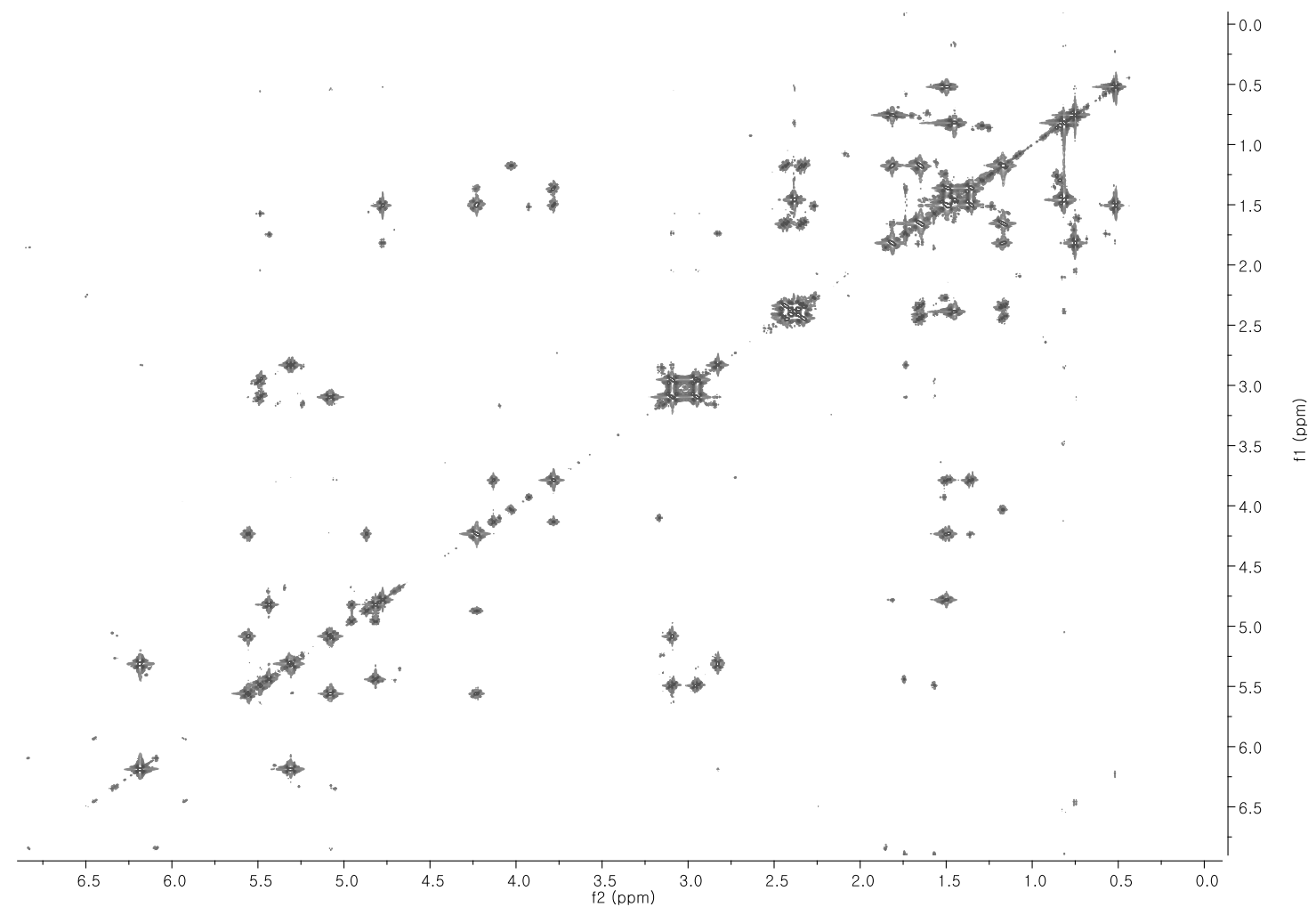

Figure S10. HR-ESI-MS data of dumulmycin (1).

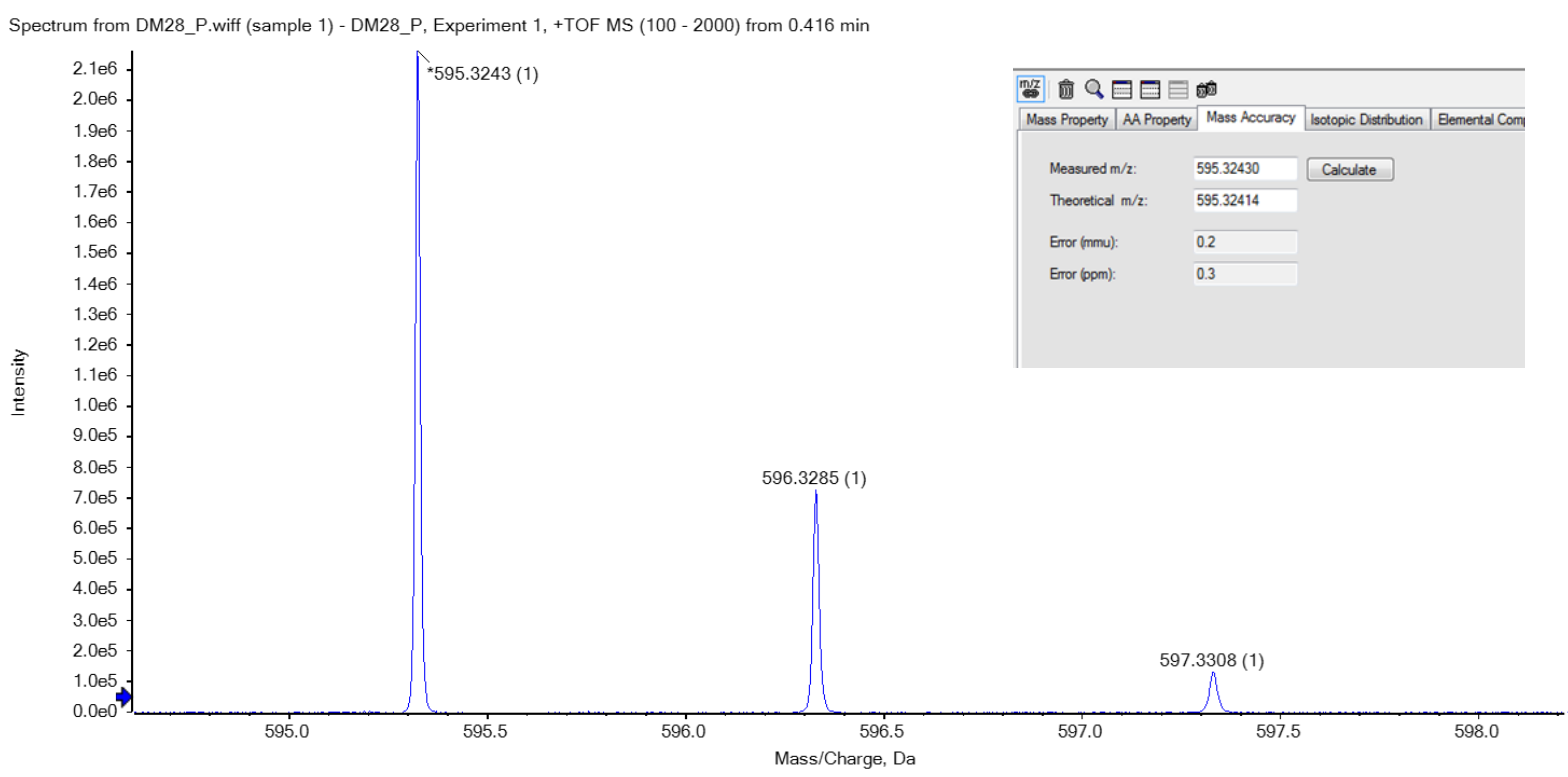




\section{Preparing MTPA esters of dumulmycin (1)}

Dumulmycin (1) was prepared in two amber vials, each containing $4 \mathrm{mg}$ of $\mathbf{1}$. They were dried under high vacuum. The compound in each vial was then dissolved in $1 \mathrm{~mL}$ of freshly distilled anhydrous pyridine. This was followed by the addition of $(R)$ - and $(S)$ - $\alpha$-methoxy- $\alpha$-(trifluoromethyl)phenylacetyl chloride $((R)$ - and $(S)$-MTPA-Cl) $(25 \mu \mathrm{L})$. The reaction mixtures were stirred at room temperature $(\mathrm{rt})$ for $20 \mathrm{~min} ; 30 \mu \mathrm{L}$ of $\mathrm{MeOH}$ was then injected into each vial to quench the reaction. After quenching, the products were purified using an HPLC column (Kromasil 100-5-C18, $10 \times 250 \mathrm{~mm}, 5 \mu \mathrm{m}$ ) under reversed-phase gradient conditions $\left(70 \% \mathrm{CH}_{3} \mathrm{CN}-\mathrm{H}_{2} \mathrm{O}\right.$ to $100 \% \mathrm{CH}_{3} \mathrm{CN}-\mathrm{H}_{2} \mathrm{O}$ over $30 \mathrm{~min}$, UV detection at $230 \mathrm{~nm}$, flow rate: $2 \mathrm{~mL} / \mathrm{min})$. The tetra- $(S)$-MTPA ester (1a) tetra-(R)-MTPA ester (1) b) of 1 eluted at 43.6 and $44.5 \mathrm{~min}$, respectively. Both $\mathbf{1 a}$ and $\mathbf{1 b}$ were further purified under reverse-phase step gradient conditions $\left(93 \% \mathrm{CH}_{3} \mathrm{CN}-\mathrm{H}_{2} \mathrm{O}\right.$ for 30 min and then $97 \% \mathrm{CH}_{3} \mathrm{CN}-\mathrm{H}_{2} \mathrm{O}$ isocratic, UV detection at $230 \mathrm{~nm}$, flow rate: $2 \mathrm{~mL} / \mathrm{min}$ ) using the same HPLC column used previously. Purified 1a and $\mathbf{1 b}$ eluted at $43.4 \mathrm{~min}(0.7 \mathrm{mg})$ and $41.2 \mathrm{~min}(0.6 \mathrm{mg})$, respectively. The molecular formulas of tetra- $(S)$ and $(R)$-MTPA ester (1a and $\mathbf{1 b})$ of $\mathbf{1}$ were confirmed to be $\mathrm{C}_{73} \mathrm{H}_{76} \mathrm{~F}_{12} \mathrm{O}_{16}$ by HR-ESI-MS [M+Na] ${ }^{+} \mathrm{m} / \mathrm{z}$ 1459.4898 for $\mathbf{1 a}$ and $[\mathrm{M}+\mathrm{Na}]^{+} \mathrm{m} / z 1459.4879$ for $\mathbf{1 b}$ (calcd for $\left.\mathrm{C}_{73} \mathrm{H}_{76} \mathrm{~F}_{12} \mathrm{O}_{16} \mathrm{Na}, 1459.4834\right)$. The $\Delta \delta_{s-}$ $R$ values were calculated based on the ${ }^{1} \mathrm{H}$ and COSY NMR data for $\mathbf{1 a}$ and $\mathbf{1 b}$.

Tetra-(S)-MTPA ester (1a) $(0.7 \mathrm{mg}):{ }^{1} \mathrm{H}$ NMR (DMSO- $\left.d_{6}, 800 \mathrm{MHz}\right) \delta_{\mathrm{H}} 7.560-7.437(20 \mathrm{H}, \mathrm{m}), 6.453$ $(1 \mathrm{H}, \mathrm{d}, J=15.0 \mathrm{~Hz}), 6.263(1 \mathrm{H}, \mathrm{d}, J=9.0 \mathrm{~Hz}) 5.727(1 \mathrm{H}, \mathrm{m}), 5.700(1 \mathrm{H}, \mathrm{m}), 5.681(1 \mathrm{H}, \mathrm{m}), 5.659(1 \mathrm{H}$, d, $J=8.7 \mathrm{~Hz}), 5.548(1 \mathrm{H}, \mathrm{m}), 5.532(1 \mathrm{H}, \mathrm{m}), 5.083(1 \mathrm{H}, \mathrm{m}), 4.725(1 \mathrm{H}, \mathrm{d}, J=9.9 \mathrm{~Hz}), 3.633(3 \mathrm{H}, \mathrm{s})$, $3.545(3 \mathrm{H}, \mathrm{s}), 3.488(3 \mathrm{H}, \mathrm{s}), 3.479(3 \mathrm{H}, \mathrm{s}), 3.443(1 \mathrm{H}, \mathrm{m}), 3.278(1 \mathrm{H}, \mathrm{m}), 3.259(1 \mathrm{H}, \mathrm{m}), 3.083(1 \mathrm{H}$, dd, $J=16.5,8.3 \mathrm{~Hz}), 2.320-2.222(4 \mathrm{H}, \mathrm{m}), 2.024(1 \mathrm{H}, \mathrm{m}), 2.010(1 \mathrm{H}, \mathrm{m}), 1.996(1 \mathrm{H}, \mathrm{m}), 1.968(3 \mathrm{H}$, s), $1.843(3 \mathrm{H}, \mathrm{s}), 1.566(1 \mathrm{H}, \mathrm{m}), 1.529(1 \mathrm{H}, \mathrm{m}), 1.479(3 \mathrm{H}, \mathrm{s}), 1.415(2 \mathrm{H}, \mathrm{m}), 1.147(1 \mathrm{H}, \mathrm{m}), 0.761(3 \mathrm{H}$, t, $J=7.5 \mathrm{~Hz}), 0.693(3 \mathrm{H}, \mathrm{d}, J=5.8 \mathrm{~Hz}), 0.600(3 \mathrm{H}, \mathrm{d}, J=6.9 \mathrm{~Hz})$

Tetra-( $R$ )-MTPA ester (1b) $(0.6 \mathrm{mg}):{ }^{1} \mathrm{H}$ NMR (DMSO- $\left.d_{6}, 850 \mathrm{MHz}\right) \delta_{\mathrm{H}} 7.552-7.406(20 \mathrm{H}, \mathrm{m}), 6.407$ $(1 \mathrm{H}, \mathrm{d}, J=15.0 \mathrm{~Hz}), 6.265(1 \mathrm{H}, \mathrm{d}, J=8.8 \mathrm{~Hz}), 5.875(1 \mathrm{H}, \mathrm{dd}, J=10.0,10.0 \mathrm{~Hz}), 5.757(1 \mathrm{H}, \mathrm{m}), 5.714$ $(1 \mathrm{H}, \mathrm{m}), 5.605(1 \mathrm{H}, \mathrm{m}), 5.561(1 \mathrm{H}, \mathrm{dd}, J=10.5,10.5 \mathrm{~Hz}), 5.481(1 \mathrm{H}, \mathrm{d}, J=8.8 \mathrm{~Hz}), 5.031(1 \mathrm{H}, \mathrm{d}, J=$ $9.1 \mathrm{~Hz}), 4.608(1 \mathrm{H}, \mathrm{d}, J=10.5 \mathrm{~Hz}), 3.623(3 \mathrm{H}, \mathrm{s}), 3.469(3 \mathrm{H}, \mathrm{s}), 3.446(3 \mathrm{H}, \mathrm{s}), 3.427(3 \mathrm{H}, \mathrm{s}), 3.357$ $(1 \mathrm{H}, \mathrm{m}), 3.301(1 \mathrm{H}, \mathrm{m}), 3.255(1 \mathrm{H}, \mathrm{dd}, J=16.8,7.5 \mathrm{~Hz}), 3.103(1 \mathrm{H}, \mathrm{dd}, J=16.8,8.4 \mathrm{~Hz}), 2.383-2.311$ $(4 \mathrm{H}, \mathrm{m}), 2.102-2.011(3 \mathrm{H}, \mathrm{m}) 1.943(3 \mathrm{H}, \mathrm{s}), 1.864(3 \mathrm{H}, \mathrm{s}), 1.656,(2 \mathrm{H}, \mathrm{m}), 1.586(3 \mathrm{H}, \mathrm{s}), 1.424(2 \mathrm{H}, \mathrm{m})$, $1.183(1 \mathrm{H}, \mathrm{m}), 0.760(3 \mathrm{H}, \mathrm{t}, J=7.4 \mathrm{~Hz}), 0.715(3 \mathrm{H}, \mathrm{d}, J=4.8 \mathrm{~Hz}), 0.506(3 \mathrm{H}, \mathrm{d}, J=6.5 \mathrm{~Hz})$ 
Figure S11. HR-ESI-MS data of (S)-MTPA ester product (1a).

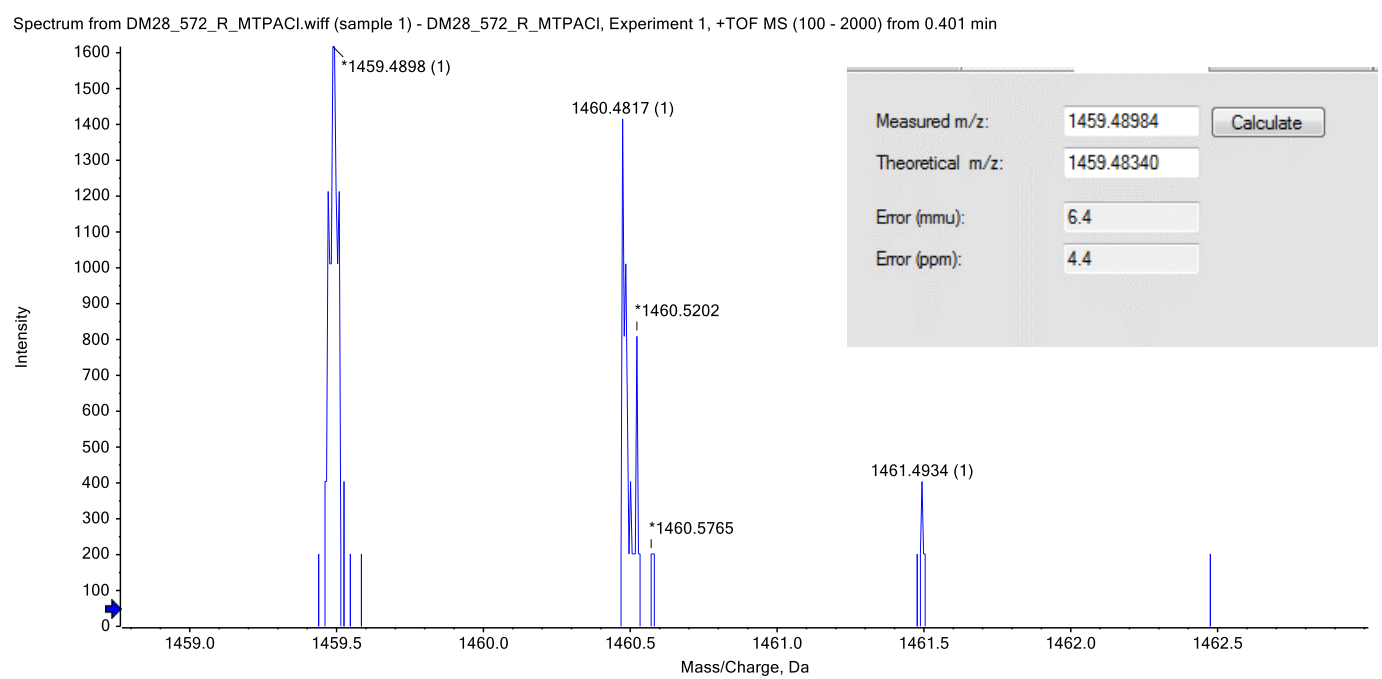

Figure S12. HR-ESI-MS data of (R)-MTPA ester product (1b).

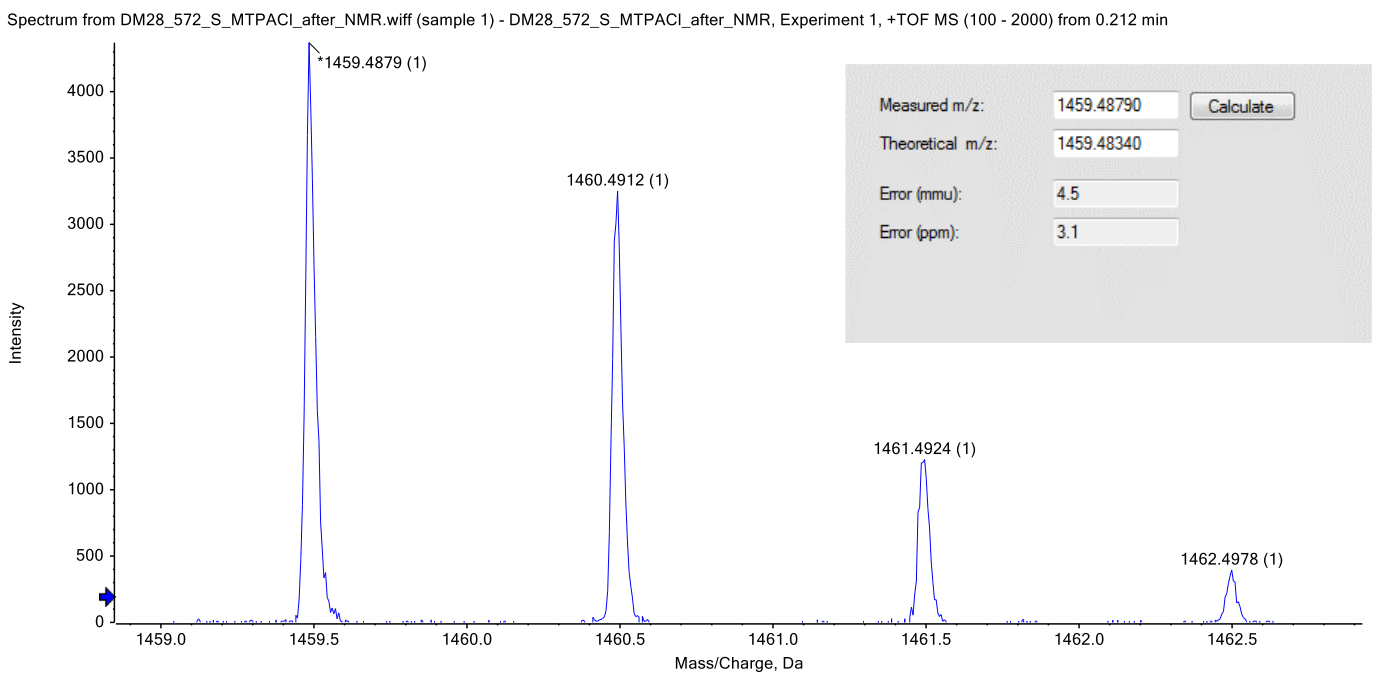


Figure S13. ${ }^{1} \mathrm{H}$ NMR spectrum of (S)-MTPA ester (1a) of 1 at $800 \mathrm{MHz}$ in DMSO- $d_{6}$.

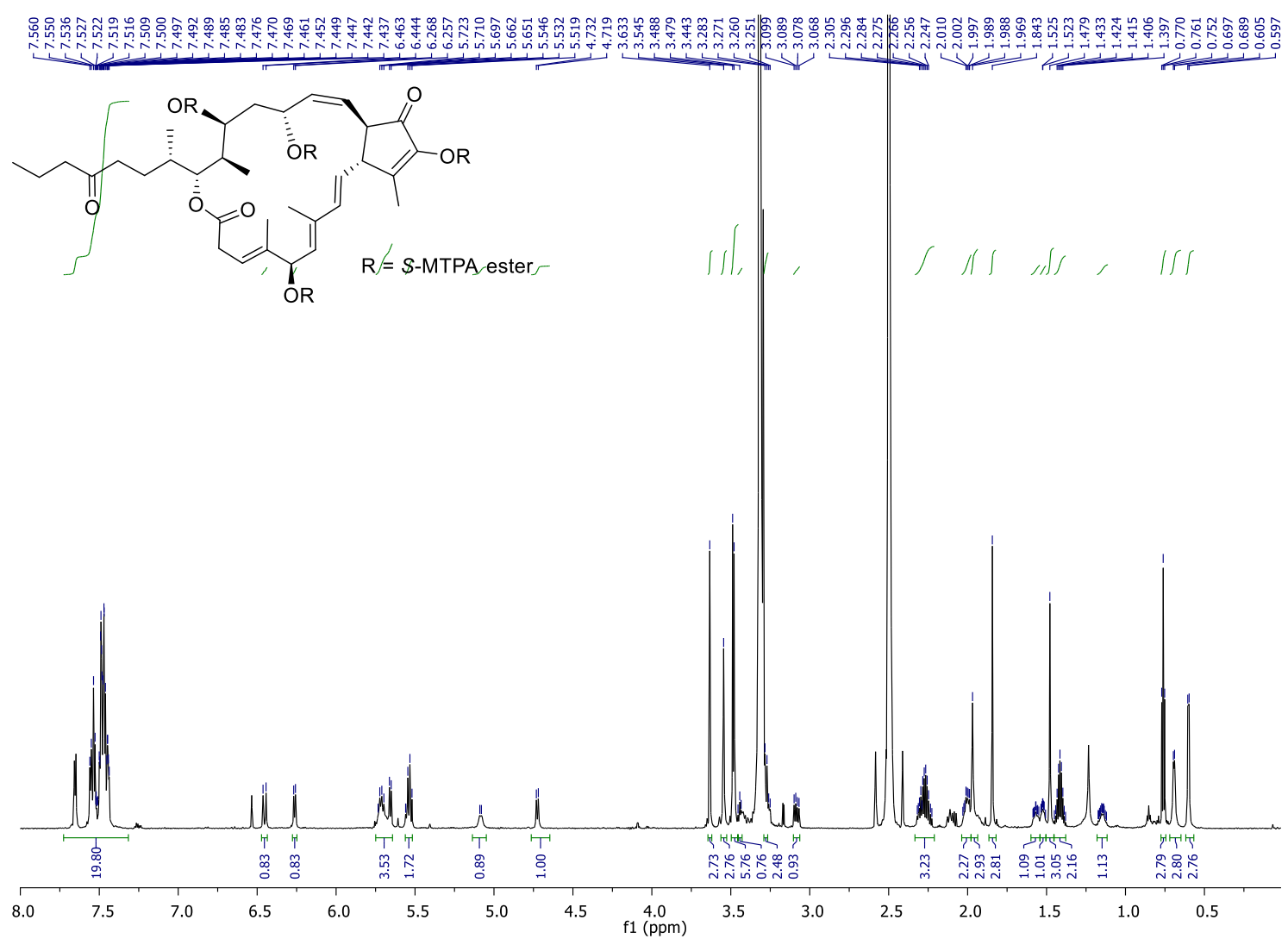

Figure S14. COSY NMR spectrum of (S)-MTPA ester (1a) of 1 at $800 \mathrm{MHz}$ in DMSO- $d_{6}$.

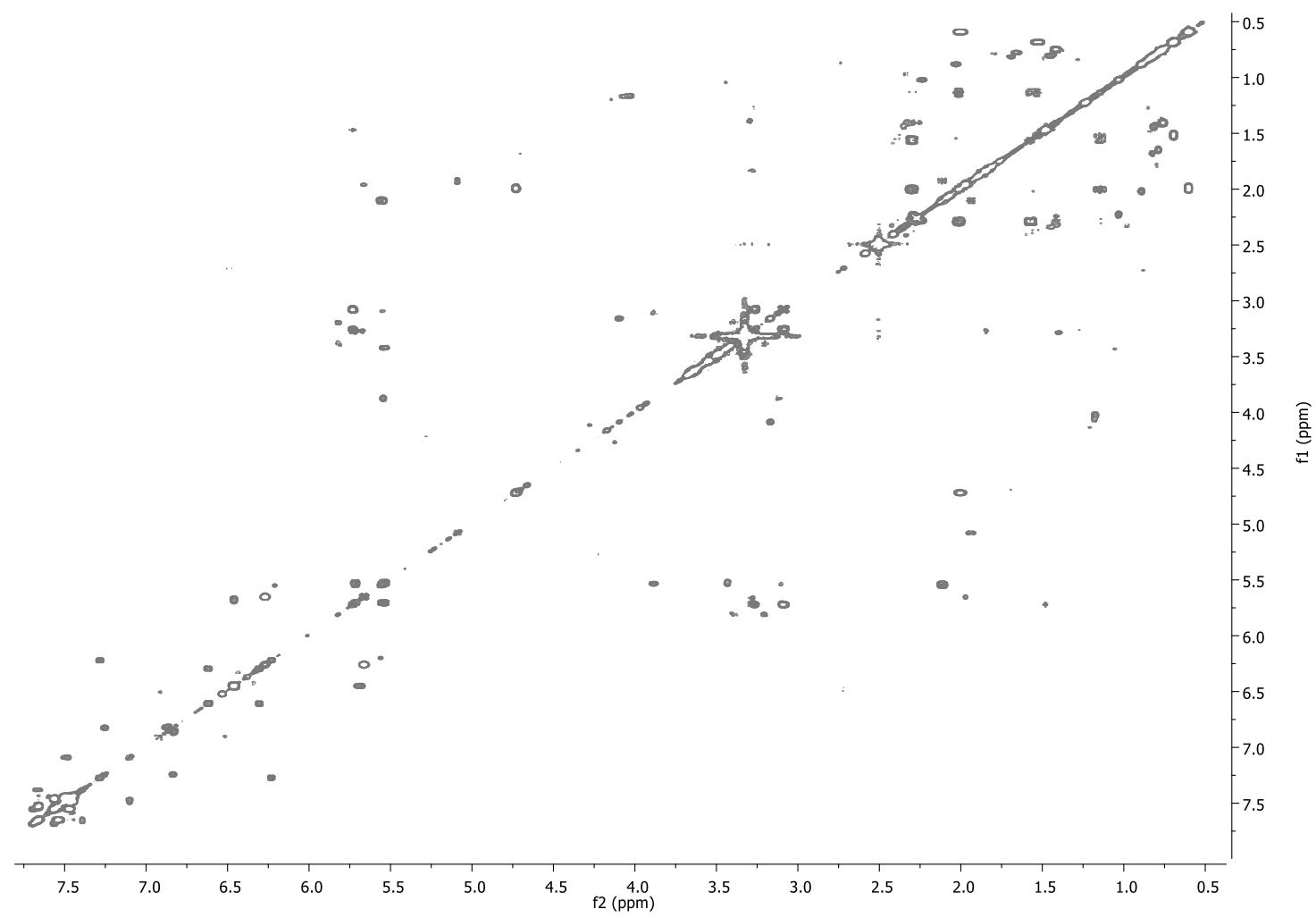


Figure S15. ${ }^{1} \mathrm{H}$ NMR spectrum data of (R)-MTPA ester (1b) of 1 at $850 \mathrm{MHz}$ in DMSO- $d 6$.

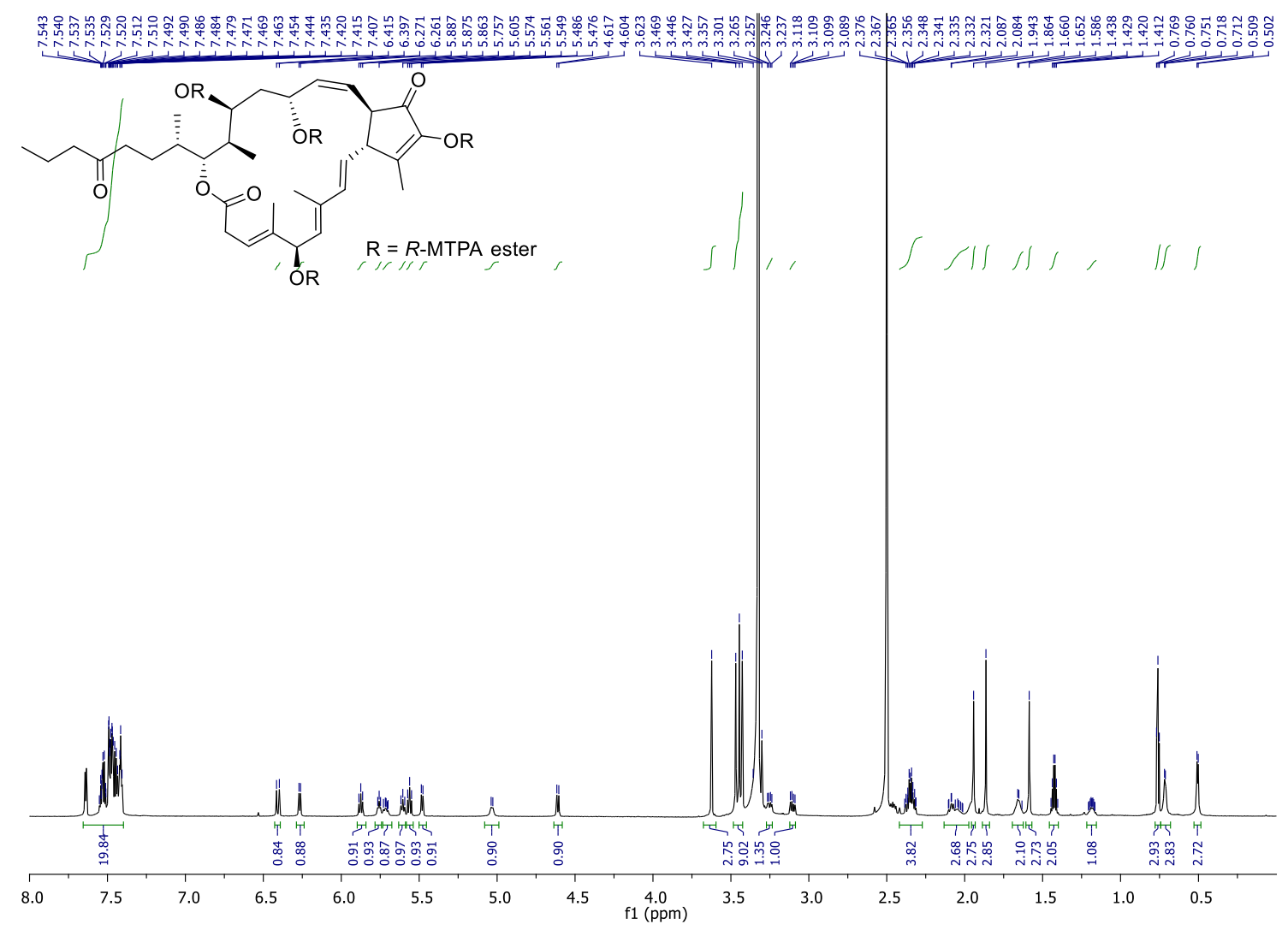

Figure S16. COSY NMR spectrum data of $(R)$-MTPA ester (1b) of 1 at $850 \mathrm{MHz}$ in DMSO- $d_{6}$.

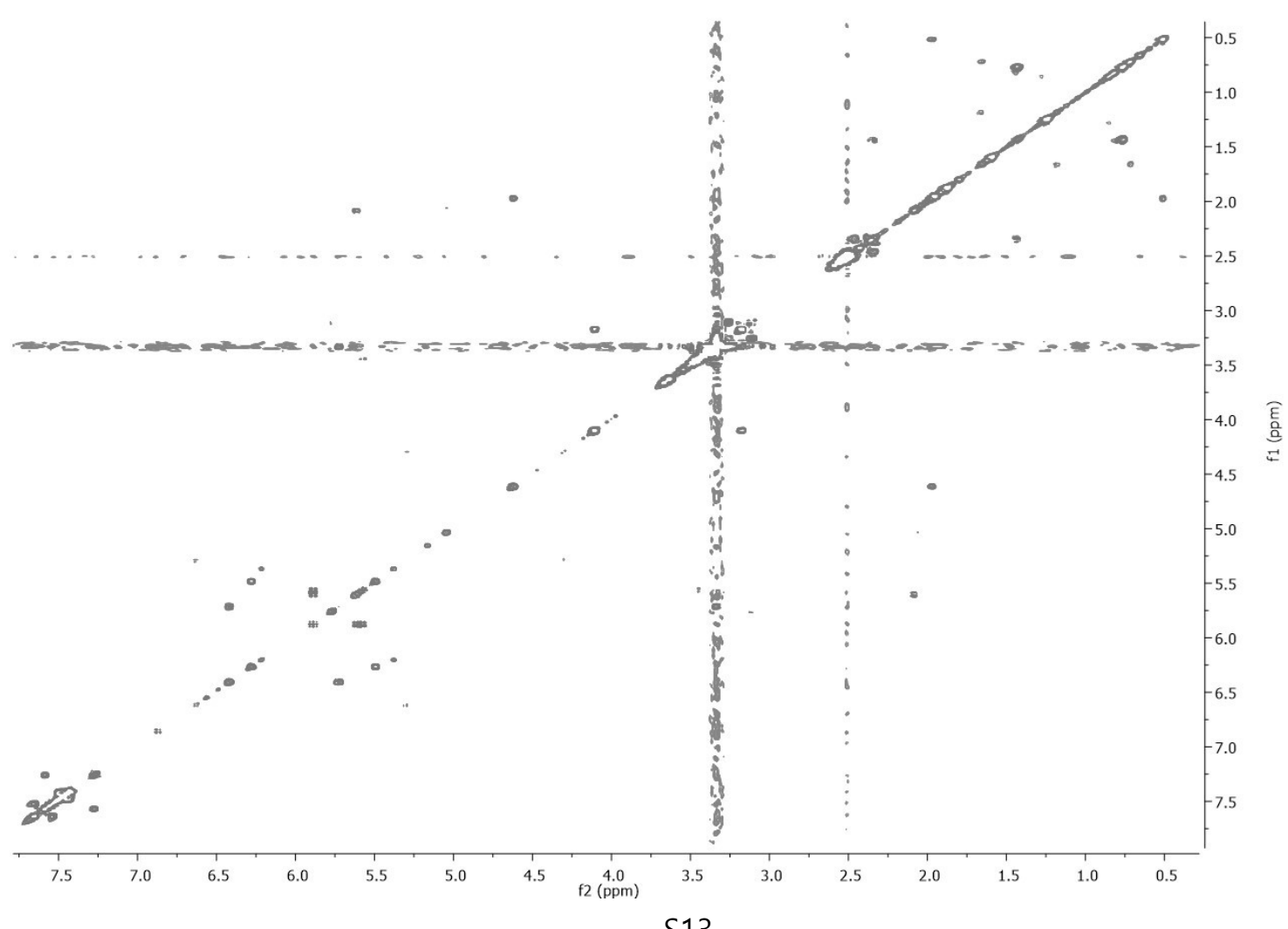




\section{Conformational search and DP4 analysis of dumulmycin (1)}

A conformational search was performed using a mixed sampling method of torsional/low-mode using Macromodel (version 9.9, Schrödinger LLC) with the Merk molecular force field (MMFF). ${ }^{3}$ The upper limit of the relative potential energy was $10 \mathrm{~kJ} / \mathrm{mol}$. A total of 44 diastereomers were obtained. The Boltzmann population of each conformer was calculated. The basis set for the calculation was def-SV(P) for all atoms and the level of theory was B3-LYP at the functional level in the gas phase. The calculated ${ }^{1} \mathrm{H}$ and ${ }^{13} \mathrm{C}$ chemical shift values were averaged using the Boltzmann populations as described previously. ${ }^{4}$ The computational shielding tensor calculated by DP4 calculations indicated that diastereomer $1 \mathrm{c}(5 R, 10 R, 14 R, 17 R, 19 S, 20 R, 21 R, 22 S)$ had a $100.0 \%$ probability based on statistical comparison.

Figure S17. Result of DP4 calculation from the simulated models of two possible diastereomers.

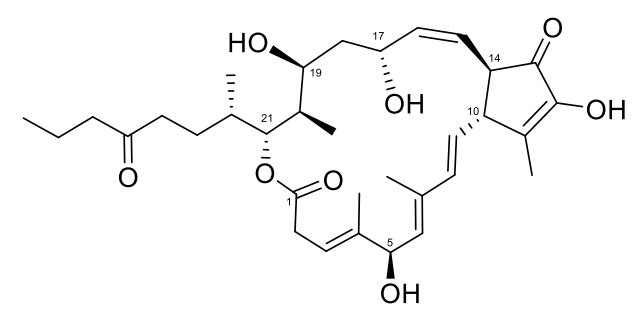

Diastereomer 1c $(5 R, 10 R, 14 R, 17 R, 19 S, 20 R, 21 R, 22 S)$

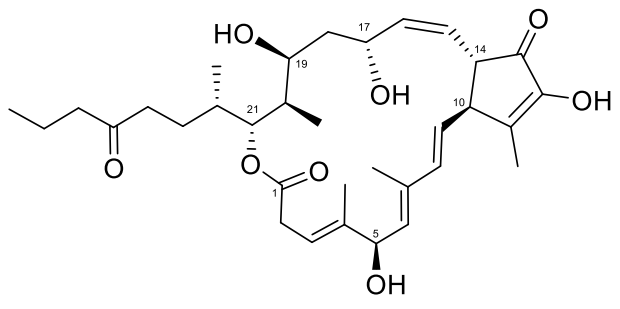

Diastereomer 1d $(5 R, 10 S, 14 S, 17 R, 19 S, 20 R, 21 R, 22 S)$

DP4 Calculation result

both carbon and proton data : Diastereomers 1c (RRRRSRRS) - $100 \%$ Diastereomers 1d (RSSRSRRS) - $0 \%$

carbon data only

Diastereomers 1c (RRRRSRRS) - 99.9\% Diastereomers 1d (RSSRSRRS) - $0.01 \%$ proton data only

Diastereomers 1c (RRRRSRRS) - $100 \%$

Diastereomers 1d (RRRRSRRS) - $0 \%$ 
Table S2. The major conformers of diastereomers $\mathbf{1 c}$ and $\mathbf{1 d}$ of dumulmycin (1) identified by conformational searches in MMFF94 force field using MacroModel.

\begin{tabular}{|c|c|}
\hline Conformers $^{a}$ & Boltzmann population $(\%)^{b}$ \\
\hline Diastereomers 1c_1 & 6.400 \\
\hline Diastereomers $1 \mathbf{c}^{-} 2$ & 6.250 \\
\hline Diastereomers 1c_3 & 5.624 \\
\hline Diastereomers $1 c^{-} 4$ & 5.513 \\
\hline Diastereomers 1c_5 & 5.164 \\
\hline Diastereomers $1 c^{-} 6$ & 4.773 \\
\hline Diastereomers 1c_7 & 3.987 \\
\hline Diastereomers $1 c^{-} 8$ & 3.899 \\
\hline Diastereomers 1c ${ }^{-} 9$ & 3.810 \\
\hline Diastereomers $1 \mathrm{c}-10$ & 3.716 \\
\hline Diastereomers $1 \mathrm{c} 11$ & 3.595 \\
\hline Diastereomers 1c_12 & 2.887 \\
\hline Diastereomers $1 \mathbf{c}^{-} 13$ & 2.694 \\
\hline Diastereomers 1c_14 & 2.645 \\
\hline Diastereomers $1 c^{-} 15$ & 2.574 \\
\hline Diastereomers 1c_16 & 2.569 \\
\hline Diastereomers $1 \mathbf{c}^{-} 17$ & 2.547 \\
\hline Diastereomers 1c 18 & 2.295 \\
\hline Diastereomers 1c 19 & 2.270 \\
\hline Diastereomers 1c_20 & 2.242 \\
\hline Diastereomers 1c_21 & 1.964 \\
\hline Diastereomers $1 \mathbf{c}^{-} 22$ & 1.917 \\
\hline Diastereomers 1c_23 & 1.825 \\
\hline Diastereomers 1c 24 & 1.787 \\
\hline Diastereomers 1c_25 & 1.770 \\
\hline Diastereomers $1 \mathbf{c}^{-} 26$ & 1.626 \\
\hline Diastereomers 1c_27 & 1.585 \\
\hline Diastereomers 1c_28 & 1.477 \\
\hline Diastereomers 1c_29 & 1.472 \\
\hline Diastereomers 1c_30 & 1.448 \\
\hline Diastereomers 1c_31 & 1.080 \\
\hline Diastereomers 1c_32 & 1.031 \\
\hline Diastereomers $1 \mathbf{c}^{-} 33$ & 1.011 \\
\hline Diastereomers 1c_34 & 0.972 \\
\hline Diastereomers $1 \mathbf{c}^{-} 35$ & 0.914 \\
\hline Diastereomers 1c_36 & 0.903 \\
\hline Diastereomers 1c 37 & 0.892 \\
\hline Diastereomers 1c 38 & 0.873 \\
\hline Diastereomers 1d 1 & 38.321 \\
\hline Diastereomers 1d_2 & 34.227 \\
\hline Diastereomers 1d 3 & 9.053 \\
\hline Diastereomers 1d_-4 & 6.408 \\
\hline Diastereomers 1d_5 & 6.143 \\
\hline Diastereomers $1 \mathbf{d}^{-} 6$ & 5.848 \\
\hline
\end{tabular}


Table S3. Experimental (Exp.) and calculated (Cal.) chemical shift values (CS, $\delta$ ) of diastereomers 1c and $\mathbf{1 d}$ of dumulmycin (1).

\begin{tabular}{|c|c|c|c|}
\hline Position & Exp. CS of dumulmycin & $\begin{array}{c}\text { Cal. CS of } \\
\text { diastereomers 1c }\end{array}$ & $\begin{array}{c}\text { Cal. CS of } \\
\text { diastereomers 1d }\end{array}$ \\
\hline $\mathrm{C}-1$ & 170.8 & 173.52 & 173.21 \\
\hline $\mathrm{C}-2$ & 33.2 & 38.84 & 38.93 \\
\hline C-3 & 115.8 & 122.05 & 121.63 \\
\hline $\mathrm{C}-4$ & 141.3 & 145.95 & 144.65 \\
\hline $\mathrm{C}-5$ & 72.2 & 75.18 & 72.99 \\
\hline C-6 & 134.0 & 140.32 & 134.39 \\
\hline C-7 & 131.6 & 133.3 & 136.3 \\
\hline $\mathrm{C}-8$ & 136.2 & 138.39 & 136.54 \\
\hline C-9 & 129.5 & 133.52 & 135.49 \\
\hline $\mathrm{C}-10$ & 50.3 & 56.4 & 57.38 \\
\hline $\mathrm{C}-11$ & 144.5 & 145.06 & 144.02 \\
\hline $\mathrm{C}-12$ & 148.5 & 146.68 & 147.17 \\
\hline $\mathrm{C}-13$ & 201.4 & 204.03 & 203.83 \\
\hline $\mathrm{C}-14$ & 49.4 & 54 & 51.71 \\
\hline $\mathrm{C}-15$ & 126.0 & 131.65 & 130.95 \\
\hline $\mathrm{C}-16$ & 137.9 & 141.4 & 141.49 \\
\hline $\mathrm{C}-17$ & 65.0 & 67.19 & 68.73 \\
\hline $\mathrm{C}-18$ & 43.5 & 49.75 & 46.36 \\
\hline C-19 & 67.3 & 72.19 & 71.1 \\
\hline $\mathrm{C}-20$ & 37.8 & 43.03 & 42.24 \\
\hline $\mathrm{C}-21$ & 79.3 & 79.1 & 79.8 \\
\hline $\mathrm{C}-22$ & 32.3 & 38.71 & 39.5 \\
\hline $\mathrm{C}-23$ & 23.3 & 35.27 & 36.2 \\
\hline $\mathrm{C}-24$ & 39.9 & 44.02 & 45.0 \\
\hline $\mathrm{C}-25$ & 210.6 & 215.72 & 213.98 \\
\hline $\mathrm{C}-26$ & 43.7 & 48.64 & 48.3 \\
\hline $\mathrm{C}-27$ & 16.7 & 23.66 & 23.6 \\
\hline $\mathrm{C}-28$ & 13.6 & 19.81 & 19.8 \\
\hline $\mathrm{C}-29$ & 11.7 & 19.96 & 19.77 \\
\hline $\mathrm{C}-30$ & 12.8 & 19.11 & 22.08 \\
\hline C-31 & 12.4 & 18.33 & 18.48 \\
\hline C-32 & 8.7 & 16.25 & 15.88 \\
\hline C-33 & 16.6 & 22.57 & 21.9 \\
\hline $\mathrm{H}_{2}-2 \mathrm{a}$ & 3.09 & 2.59 & 2.65 \\
\hline $\mathrm{H}_{2}-2 \mathrm{~b}$ & 2.95 & 2.39 & 2.26 \\
\hline $\mathrm{H}-3$ & 5.48 & 5.42 & 5.43 \\
\hline H-5 & 4.81 & 4.52 & 4.39 \\
\hline H-6 & 5.43 & 5.13 & 4.88 \\
\hline H-8 & 6.18 & 5.71 & 5.43 \\
\hline H-9 & 5.31 & 4.61 & 4.94 \\
\hline H-10 & 2.83 & 2.4 & 2.3 \\
\hline H-14 & 3.08 & 2.35 & 2.36 \\
\hline H-15 & 5.08 & 4.61 & 4.55 \\
\hline H-16 & 5.55 & 5.22 & 5.18 \\
\hline $\mathrm{H}-17$ & 4.23 & 3.92 & 3.72 \\
\hline $\mathrm{H}_{2}-18 \mathrm{a}$ & 1.50 & 1.38 & 0.81 \\
\hline
\end{tabular}




\begin{tabular}{|c|c|c|c|}
\hline $\mathrm{H}_{2}-18 \mathrm{~b}$ & 1.36 & 1.13 & 1.72 \\
\hline H-19 & 3.78 & 3.77 & 3.88 \\
\hline H-20 & 1.50 & 1.42 & 1.62 \\
\hline H-21 & 4.77 & 4.8 & 4.72 \\
\hline H-22 & 1.82 & 1.6 & 1.6 \\
\hline $\mathrm{H}_{2}-23 \mathrm{a}$ & 1.65 & 1.28 & 1.3 \\
\hline $\mathrm{H}_{2}-23 \mathrm{~b}$ & 1.17 & 0.89 & 1.2 \\
\hline $\mathrm{H}_{2}-24 \mathrm{a}$ & 2.43 & 2.4 & 2.2 \\
\hline $\mathrm{H}_{2}-24 \mathrm{~b}$ & 2.34 & 1.78 & 1.8 \\
\hline $\mathrm{H}_{2}-26$ & 2.38 & 1.85 & 2.03 \\
\hline $\mathrm{H}_{2}-26$ & 2.38 & 1.93 & 1.86 \\
\hline $\mathrm{H}_{2}-27$ & 1.45 & 1.18 & 1.33 \\
\hline $\mathrm{H}_{2}-27$ & 1.45 & 1.1 & 0.98 \\
\hline $\mathrm{H}_{3}-28$ & 0.81 & 0.48 & 0.6 \\
\hline $\mathrm{H}_{3}-28$ & 0.81 & 0.41 & 0.3 \\
\hline $\mathrm{H}_{3}-28$ & 0.81 & 0.69 & 0.8 \\
\hline $\mathrm{H}_{3}-29$ & 1.57 & 1.12 & 0.94 \\
\hline $\mathrm{H}_{3}-29$ & 1.57 & 1.32 & 1.26 \\
\hline $\mathrm{H}_{3}-29$ & 1.57 & 1.45 & 1.68 \\
\hline $\mathrm{H}_{3}-30$ & 1.75 & 1.24 & 1.43 \\
\hline $\mathrm{H}_{3}-30$ & 1.75 & 1.58 & 1.07 \\
\hline $\mathrm{H}_{3}-30$ & 1.75 & 1.17 & 1.17 \\
\hline $\mathrm{H}_{3}-31$ & 1.74 & 0.97 & 0.97 \\
\hline $\mathrm{H}_{3}-31$ & 1.74 & 2.06 & 1.98 \\
\hline $\mathrm{H}_{3}-31$ & 1.74 & 1.24 & 1.24 \\
\hline $\mathrm{H}_{3}-32$ & 0.52 & 0.52 & 0.51 \\
\hline $\mathrm{H}_{3}-32$ & 0.52 & 0.58 & 0.4 \\
\hline $\mathrm{H}_{3}-32$ & 0.52 & 0.42 & -0.03 \\
\hline $\mathrm{H}_{3}-33$ & 0.75 & 0.64 & 0.7 \\
\hline $\mathrm{H}_{3}-33$ & 0.75 & 0.68 & 1.07 \\
\hline $\mathrm{H}_{3}-33$ & 0.75 & 0.5 & 0.54 \\
\hline $5-\mathrm{OH}$ & 4.95 & -0.44 & -0.66 \\
\hline $12-\mathrm{OH}$ & 9.15 & 3.83 & 3.76 \\
\hline $17-\mathrm{OH}$ & 4.86 & 0.19 & -0.38 \\
\hline $19-\mathrm{OH}$ & 4.13 & 0.12 & -0.49 \\
\hline
\end{tabular}


Genome Sequencing of Streptomyces sp. DM28

The whole genome of Streptomyces sp. DM28, which produces dumulmycin (1), was sequenced using the PacBio ${ }^{\circledR}$ RS II system (Pacific Biosciences, Menlo Park, CA) in Chunlab Inc. (Seoul, Republic of Korea). ${ }^{5}$ The whole genome was assembled using PacBio SMRT ${ }^{\circledR}$ Analysis 2.3.0 (Pacific Bioscience, USA) ${ }^{6}$ with the hierarchical genome assembly process (HGAP). The biosynthetic gene clusters of dumulmycin (1) were scrutinized using antiSMASH. ${ }^{7}$ 
Table S4. Putative functions of genes in the dumulmycin (1) biosynthetic gene cluster.

\begin{tabular}{|c|c|c|c|c|}
\hline \multirow[b]{2}{*}{ Gene } & \multirow[b]{2}{*}{ Size $[\mathrm{bp}](\mathrm{aa})$} & \multirow[b]{2}{*}{ Putative function } & \multicolumn{2}{|c|}{ Best match } \\
\hline & & & $\begin{array}{l}\text { Organisms / GeneBank } \\
\text { (residue) }\end{array}$ & $\begin{array}{c}\text { Identity }[\%] / \text { similarity } \\
{[\%]}\end{array}$ \\
\hline orf146 & $987(328)$ & LysR family transcriptional regulator & $\begin{array}{l}\text { Streptomyces toyocaensis / } \\
\text { WP } 037928758.1(299)\end{array}$ & $94 / 96$ \\
\hline orf147 & $939(312)$ & NAD-dependent epimerase/hydratase family protein & $\begin{array}{l}\text { Streptomyces toyocaensis / } \\
\text { WP } 037928756.1(312)\end{array}$ & $87 / 90$ \\
\hline orf148 & $903(248)$ & aldo/keto reductase & $\begin{array}{l}\text { Streptomyces toyocaensis / } \\
\text { WP } 037928754.1(294)\end{array}$ & $91 / 95$ \\
\hline orf150 & $168(55)$ & hypothetical protein & $\begin{array}{l}\text { Streptomyces marokkonensis } \\
\text { / WP } 167533914.1 \text { (55) }\end{array}$ & $98 / 98$ \\
\hline orf151 & $1758(585)$ & hypothetical protein & $\begin{array}{l}\text { Streptomyces sp. JHA26 / } \\
\text { WP } 077800199.1(585)\end{array}$ & $89 / 93$ \\
\hline orf152 & $1827(608)$ & $\begin{array}{l}\text { glycoside hydrolase family } 3 \mathrm{C} \text {-terminal domain-containing } \\
\text { protein }\end{array}$ & $\begin{array}{l}\text { Streptomyces marokkonensis } \\
\text { / WP } 149552346.1(608)\end{array}$ & $99 / 99$ \\
\hline orf153 & $585(194)$ & dihydrofolate reductase family protein & $\begin{array}{l}\text { Streptomyces sp. IMTB } \\
\text { 2501/WP_076094670.1 } \\
(194)\end{array}$ & $92 / 96$ \\
\hline orf154 & $1233(410)$ & threonine-tRNA ligase & $\begin{array}{l}\text { Streptomyces toyocaensis / } \\
\text { WP 037928956.1 (416) }\end{array}$ & $91 / 95$ \\
\hline orf155 & $1656(551)$ & multicopper oxidase domain-containing protein & $\begin{array}{l}\text { Streptomyces marokkonensis } \\
\text { / WP } 149552347.1 \text { (550) }\end{array}$ & $198 / 98$ \\
\hline$d u l F$ & $3900(1299)$ & SDR family NAD(P)-dependent oxidoreductase & $\begin{array}{l}\text { Streptomyces marokkonensis } \\
\text { / WP } 149552348.1 \text { (1299) }\end{array}$ & $99 / 99$ \\
\hline$d u l G$ & $864(287)$ & SDR family NAD(P)-dependent oxidoreductase & $\begin{array}{l}\text { Streptomyces marokkonensis } \\
\text { / WP } 149552349.1 \text { (287) }\end{array}$ & $99 / 100$ \\
\hline$d u l H$ & $966(321)$ & acyltransferase domain-containing protein (AT) & $\begin{array}{l}\text { Streptomyces marokkonensis } \\
\text { / WP } 149552350.1 \text { (321) }\end{array}$ & $99 / 99$ \\
\hline$d u l M$ & $1248(415)$ & polyketide beta-ketoacyl:ACP synthase $\left(\mathrm{KS}^{*}\right)$ & $\begin{array}{l}\text { Streptomyces marokkonensis } \\
\text { / WP_ } 149552351.1(415)\end{array}$ & $99 / 99$ \\
\hline$d u l N$ & $246(81)$ & acyl carrier protein $(\mathrm{ACP})$ & $\begin{array}{l}\text { Streptomyces marokkonensis } \\
\text { / WP } 149552352.1(81)\end{array}$ & $98 / 98$ \\
\hline
\end{tabular}




\begin{tabular}{|c|c|c|c|c|}
\hline dulO & $753(250)$ & enoyl-CoA hydratase (ECH2) & $\begin{array}{l}\text { Streptomyces marokkonensis } \\
\text { / WP_149552353.1 (250) }\end{array}$ & 99/99 \\
\hline$d u l P$ & $786(261)$ & enoyl-CoA hydratase/isomerase (ECH1) & $\begin{array}{l}\text { Streptomyces marokkonensis } \\
\text { / WP } 149552354.1 \text { (261) }\end{array}$ & $98 / 100$ \\
\hline$d u l Q$ & $1260(419)$ & hydroxymethylglutaryl-CoA synthase (HCS) & $\begin{array}{l}\text { Streptomyces marokkonensis } \\
\text { / WP_149552355.1 (419) }\end{array}$ & 99/99 \\
\hline$d u l I$ & $1092(363)$ & malonyl CoA-acyl carrier protein transacylase (AT) & $\begin{array}{l}\text { Streptomyces marokkonensis } \\
\text { / WP } 149552356.1 \text { (363) }\end{array}$ & $99 / 100$ \\
\hline$d u l J$ & $1362(453)$ & $\begin{array}{l}\text { PfaD family polyunsaturated fatty acid/polyketide biosynthesis } \\
\text { protein; enoyl reductase (ER) }\end{array}$ & $\begin{array}{l}\text { Streptomyces marokkonensis } \\
\text { / WP } 149552357.1 \text { (465) }\end{array}$ & $99 / 99$ \\
\hline dulA & $9219(3072)$ & PKS (cMT-ACP-KS-DH-KR-ACP-KS-ACP-TE) & & \\
\hline$d u l B$ & $8976(2991)$ & PKS (DH-KR-ACP-KS-ACP-KS-KR) & & \\
\hline$d u l C$ & $8445(2814)$ & PKS (ACP-KS-KR-ACP-KS-ACP-ACP-KS) & & \\
\hline$d u l D$ & $13683(4560)$ & PKS (KR-ACP-KS-DH-ACP-KS-DH-KR-ACP-KS-DH-KR) & & \\
\hline$d u l E$ & $23358(7785)$ & $\begin{array}{l}\text { PKS (KS-DHt-ACP-KS-DH-KR-ACP-KS-KR-ACP-KS-DH-KR- } \\
\text { cMT-ACP-KS-KR-cMT-ACP-KS) }\end{array}$ & & \\
\hline orf171 & $342(113)$ & DUF4180 domain-containing protein & $\begin{array}{l}\text { Streptomyces marokkonensis } \\
\text { / WP } 149551170.1 \text { (127) }\end{array}$ & $100 / 100$ \\
\hline$d u l K$ & $1230(409)$ & cytochrome $\mathrm{P} 450$ & $\begin{array}{l}\text { Streptomyces marokkonensis } \\
\text { / WP } 149551171.1 \text { (409) }\end{array}$ & $99 / 99$ \\
\hline orf173 & $675(224)$ & 4'-phosphopantetheinyl transferase superfamily protein & $\begin{array}{l}\text { Streptomyces marokkonensis } \\
\text { / WP_149551172.1 (224) }\end{array}$ & 99/99 \\
\hline orf174 & $699(232)$ & restriction endonuclease & $\begin{array}{l}\text { Streptomyces marokkonensis } \\
\text { / WP_149551173.1 (232) }\end{array}$ & 97/98 \\
\hline orf175 & $1092(363)$ & peptidoglycan D-metalloendopeptidase family protein & $\begin{array}{l}\text { Streptomyces marokkonensis } \\
\text { / WP } 149551174.1 \text { (363) }\end{array}$ & $99 / 99$ \\
\hline orf176 & $2172(723)$ & hypothetical protein & $\begin{array}{l}\text { Streptomyces marokkonensis } \\
\text { / WP } 149551175.1 \text { (723) }\end{array}$ & $98 / 98$ \\
\hline orf177 & $933(310)$ & GNAT family N-acetyltransferase & $\begin{array}{l}\text { Streptomyces marokkonensis } \\
\text { / WP_149551176.1 (224) }\end{array}$ & 97/98 \\
\hline orf178 & $645(214)$ & response regulator & $\begin{array}{l}\text { Streptomyces marokkonensis } \\
\text { / WP } 167533840.1(214)\end{array}$ & 99/99 \\
\hline orf179 & $1224(407)$ & sensor histidine kinase & $\begin{array}{l}\text { Streptomyces marokkonensis } \\
\text { / WP_149551178.1 (439) }\end{array}$ & $98 / 98$ \\
\hline orf180 & $663(220)$ & VTT domain-containing protein & $\begin{array}{l}\text { Streptomyces marokkonensis } \\
\text { / WP_149551179.1 (220) }\end{array}$ & 97/98 \\
\hline
\end{tabular}




\begin{tabular}{|c|c|c|c|c|}
\hline orf181 & $681(226)$ & SUMF1/EgtB/PvdO family nonheme iron enzyme & $\begin{array}{l}\text { Streptomyces marokkonensis } \\
\text { / WP_149551180.1 (215) }\end{array}$ & $99 / 98$ \\
\hline orf182 & $1008(335)$ & hypothetical protein & $\begin{array}{l}\text { Streptomyces marokkonensis } \\
\text { / WP } 167533841.1 \text { (335) }\end{array}$ & $99 / 99$ \\
\hline orf183 & $405(134)$ & hypothetical protein & $\begin{array}{l}\text { Streptomyces marokkonensis } \\
\text { / WP } 149551181.1 \text { (215) }\end{array}$ & $96 / 98$ \\
\hline orf184 & $201(66)$ & hypothetical protein & $\begin{array}{l}\text { Streptomyces calvus / } \\
\text { MBA8948267.1 (65) }\end{array}$ & $82 / 88$ \\
\hline orf185 & $867(288)$ & SIS domain-containing protein & $\begin{array}{l}\text { Streptomyces marokkonensis } \\
\text { / WP } 149551183.1 \text { (288) }\end{array}$ & $99 / 99$ \\
\hline orf186 & $873(290)$ & $\begin{array}{l}\text { Type } 1 \text { glutamine amidotransferase-like domain-containing } \\
\text { protein }\end{array}$ & $\begin{array}{l}\text { Streptomyces marokkonensis } \\
\text { / WP } 149551184.1 \text { (432) }\end{array}$ & $98 / 98$ \\
\hline orf187 & $429(142)$ & $\begin{array}{l}\text { Type } 1 \text { glutamine amidotransferase-like domain-containing } \\
\text { protein }\end{array}$ & $\begin{array}{l}\text { Streptomyces marokkonensis } \\
\text { / WP } 149551184.1 \text { (432) }\end{array}$ & $97 / 98$ \\
\hline dulL & $1239(412)$ & M20/M25/M40 family metallo-hydrolase & $\begin{array}{l}\text { Streptomyces marokkonensis } \\
\text { / WP } 149551185.1 \text { (412) }\end{array}$ & $98 / 98$ \\
\hline orf189 & $789(262)$ & ATP-binding cassette domain-containing protein & $\begin{array}{l}\text { Streptomyces marokkonensis } \\
\text { / WP } 149551254.1(250)\end{array}$ & $99 / 100$ \\
\hline
\end{tabular}


Figure S18. Multiple sequence alignment of the amino acids of catalytic domains.

(a) Alignment of KS domains of Dul PKSs. The conserved HGTGT motif essential for decarboxylative condensation is indicated in a red box. (The amino acids of C-terminal region of KSs are omitted.)

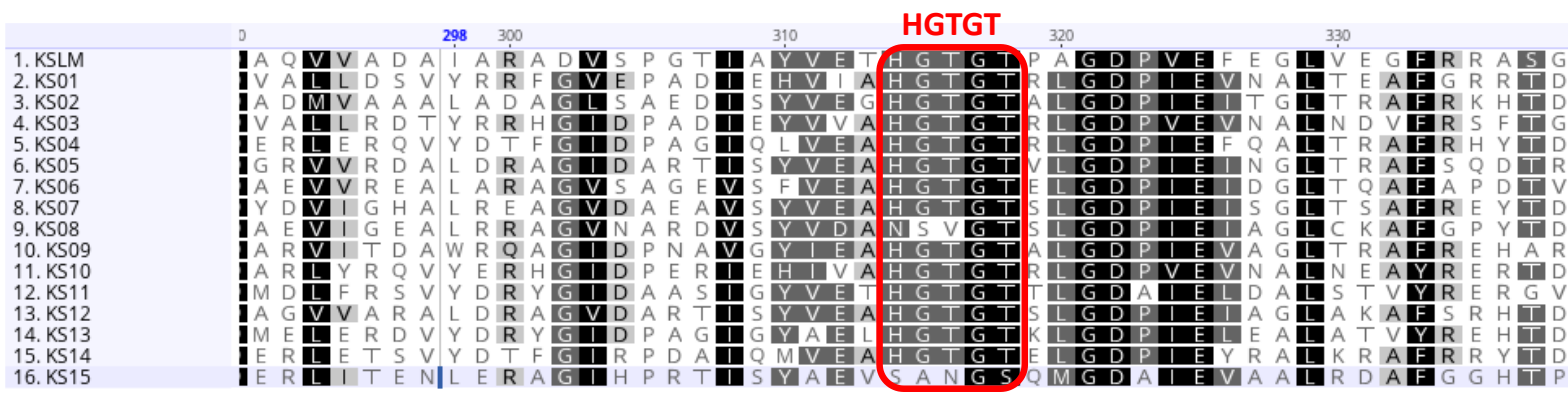

(b) Alignment of KR domains of Dul PKSs. The NADP(H) binding motif GGxGxxG is indicated in a red box. An analysis of the diagnostic Asp presence within a LDD signature motif represented in a blue box allows the classification of KR types.

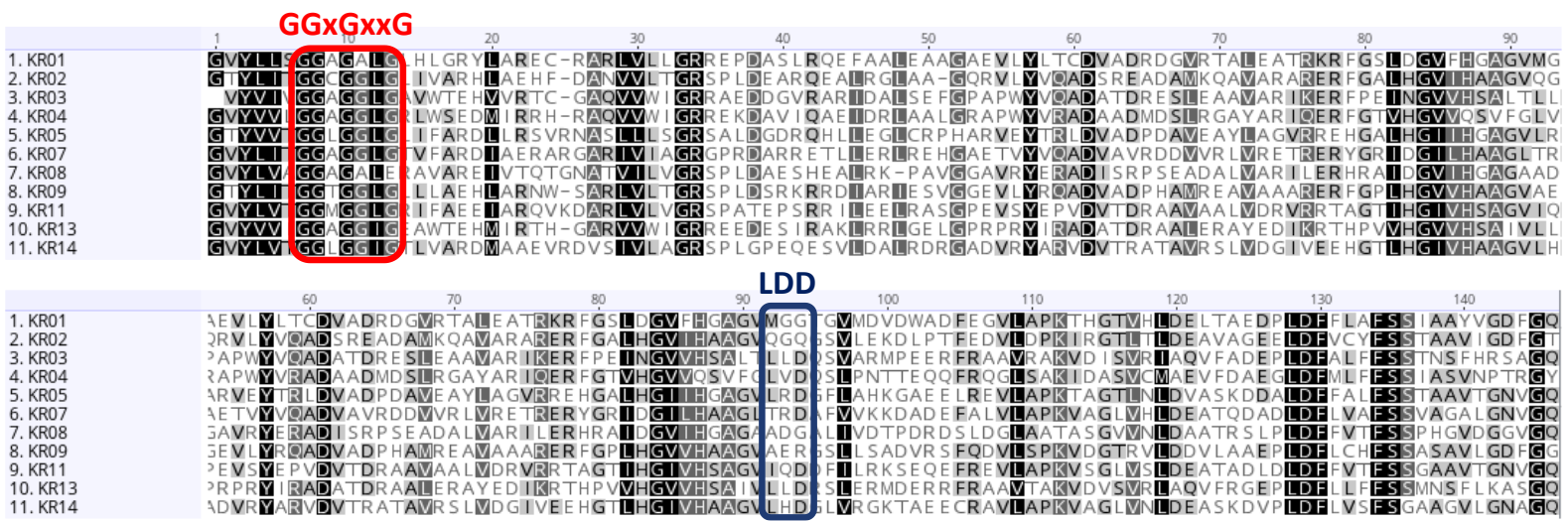

(c) Alignment of DH domains of Dul PKSs. The active motifs HxxxGxxxxP and DxxxQ/H are indicated in red boxes.

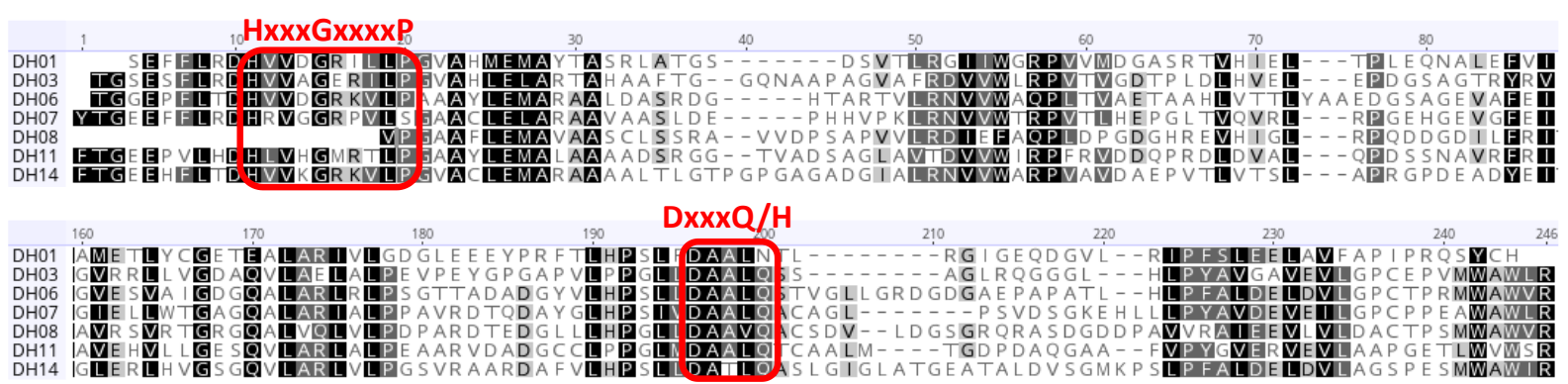


(d) Alignment of ACP domains of Dul PKSs. The conserved active GxDS motif is indicated in a red box. The Trp residue that plays an important role in recognition by the $\beta$-branching associated enzyme is conserved in tandem ACPs of modules 10 and 12, indicated in a blue box.

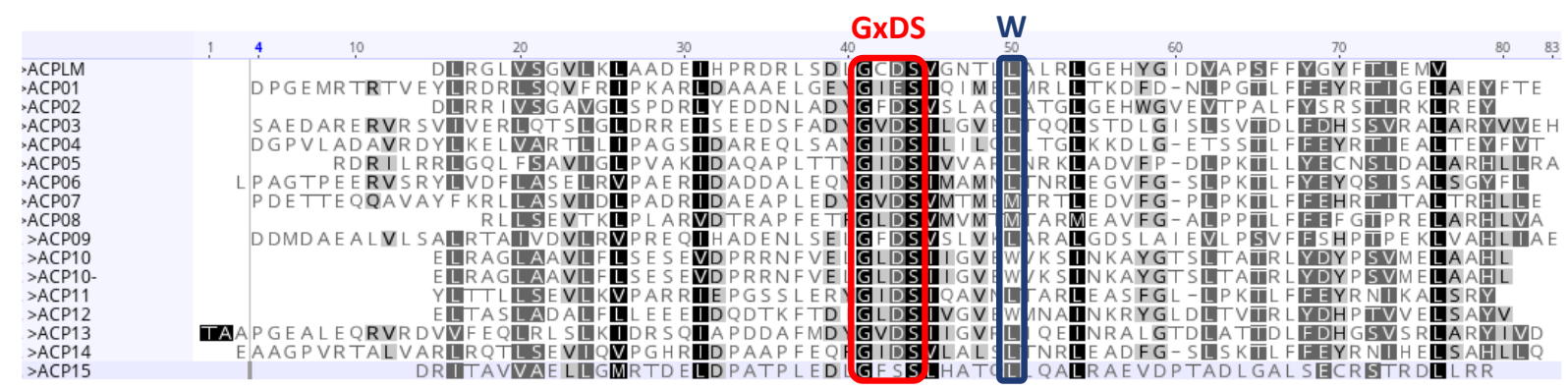

(e) Alignment of C-MT domains of Dul PKSs. The SAM-binding site motif GxGxG is indicated in red box.

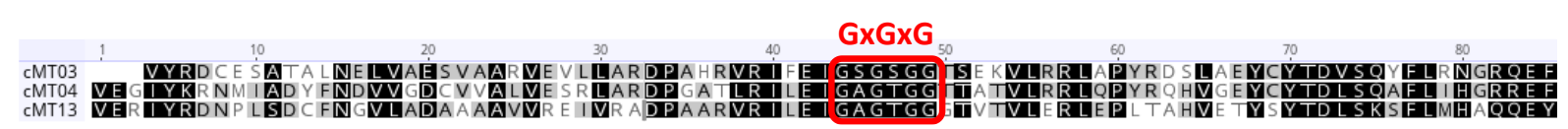


Figure S19. (a) Plausible post-modular modification of dumulmycin (1) and energy-minimized model of (b) divinyl ketone intermediate and (c) enol intermediate at B3-LYP/DFT model.

(a)
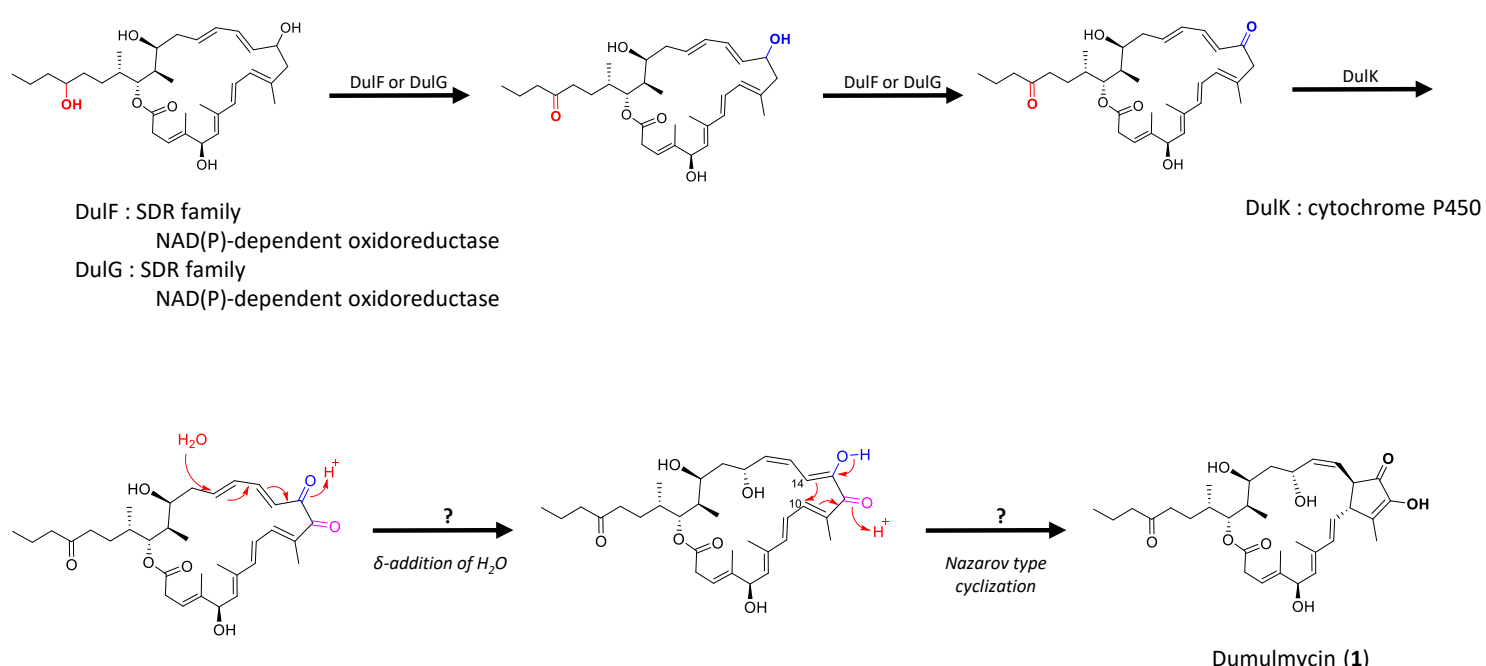

(b)

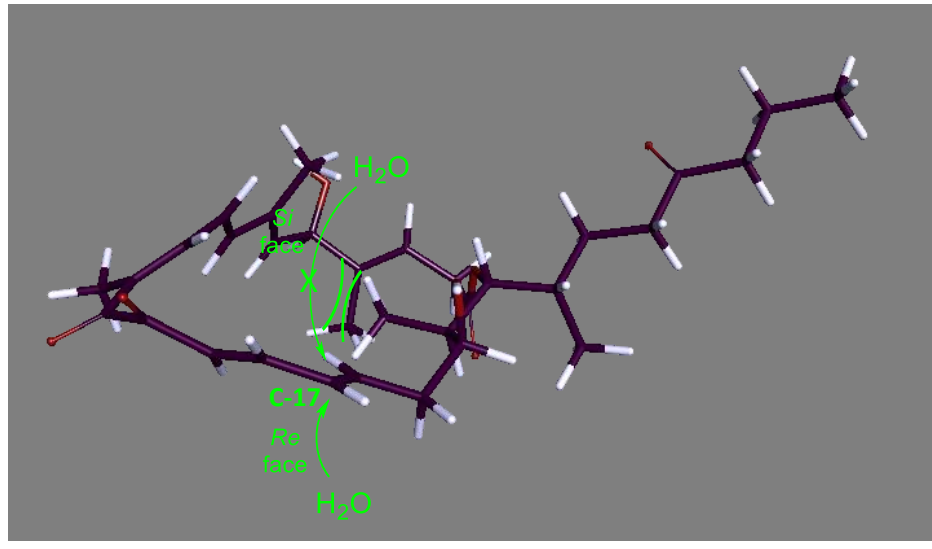

(c)

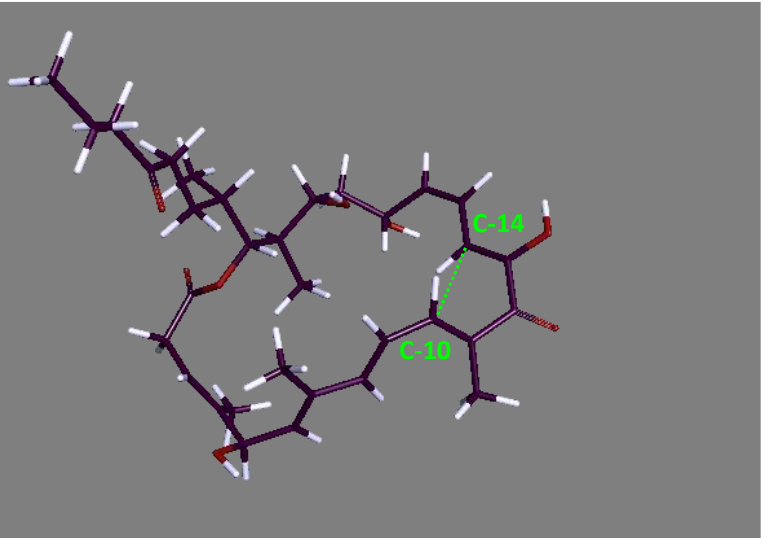


MIC determination using resazurin microtiter assay against Mycobacterium tuberculosis Mycobacterium tuberculosis $\mathrm{mc}^{2} 6230$ strain was grown at $37^{\circ} \mathrm{C}$ in Middlebrook $7 \mathrm{H} 9$ liquid medium (Difco). Additionally, $10 \%$ albumin-dextrose-catalase (ADC) and $24 \mu \mathrm{g} / \mathrm{mL}$ pantothenate were added to support the growth of $M$. tuberculosis $\mathrm{mc}^{2} 6230$. The minimum inhibitory concentration (MIC) of dumulmycin (1) was determined using the resazurin microtiter assay (REMA), as described previously. ${ }^{8}$ Briefly, exponential phase M. tuberculosis $\mathrm{mc}^{2} 6230$ was adjusted to an $\mathrm{OD}_{600}$ to 0.005 in wells of a 96-well microtiter plate. Dumulmycin (1) was added to each well using a 2-fold serial dilution method. Bedaquiline was used as the positive compound. The prepared 96-well plates were incubated at $37^{\circ} \mathrm{C}$. After 5 days, resazurin was added to each well $(0.025 \%$ [wt./vol]), and the fluorescence was measured (Ex/Em 560/590 nm) using a SpectraMax M3 multi-mode microplate reader (Molecular Devices, CA, USA). Concentrations required to inhibit bacterial growth by $50 \%$ $\left(\mathrm{MIC}_{50}\right)$ were determined using GraphPad Prism software (version 6.05; San Diego, CA, USA).

Figure S20. Determination of MIC value of dumulmycin (1) for Mycobacterium tuberculosis by resazurin microtiter assay (REMA)

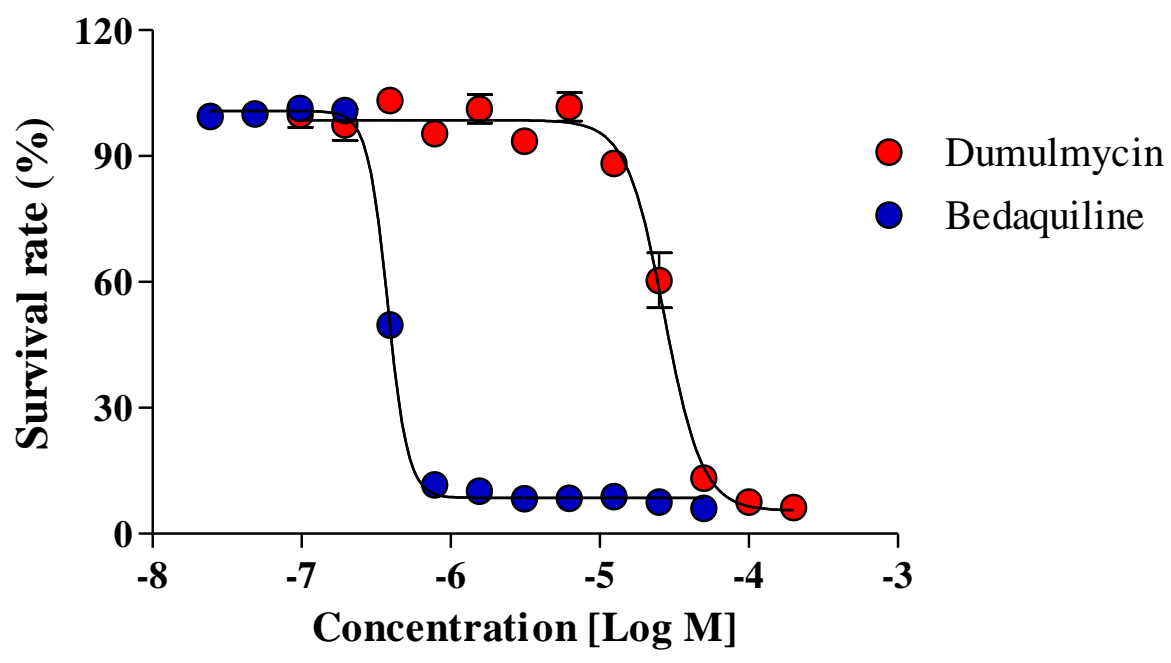


Figure S21. $J$-based configuration analysis of dumulmycin (1) at (a) C-21 and C-22, (b) C-20 and C-21, and (c) C-19 and C-20.

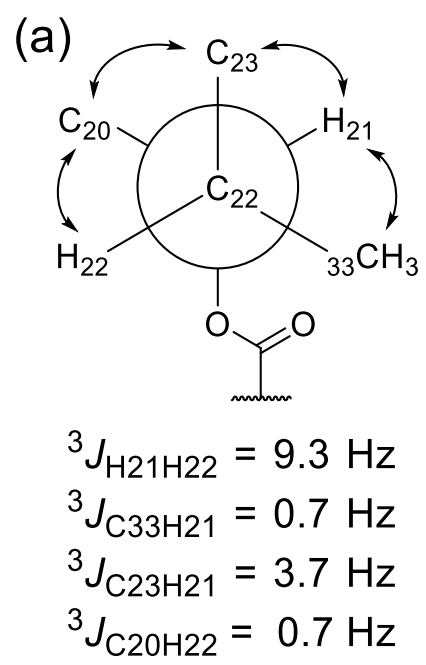

(b)

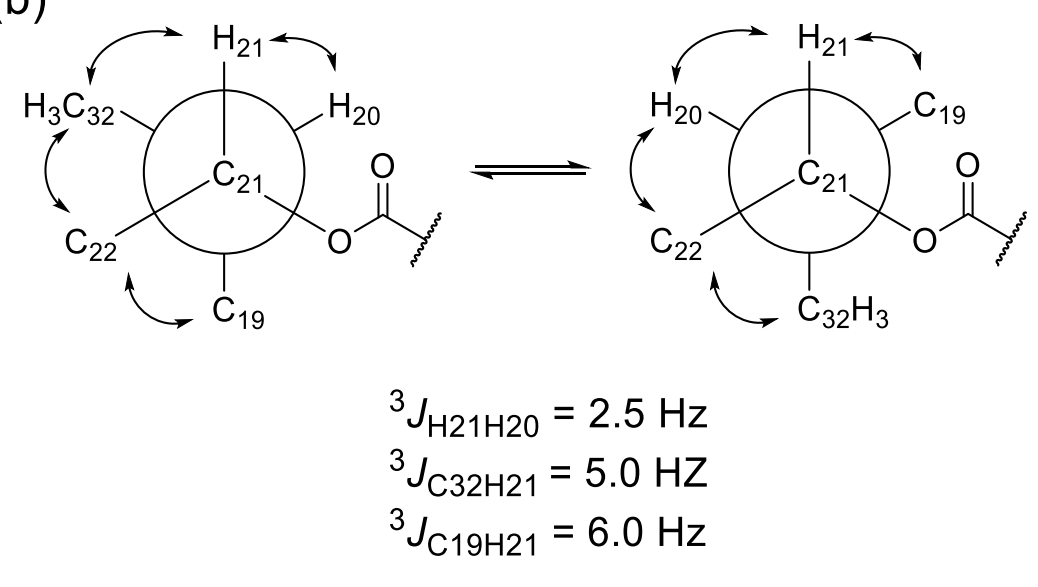

(c)

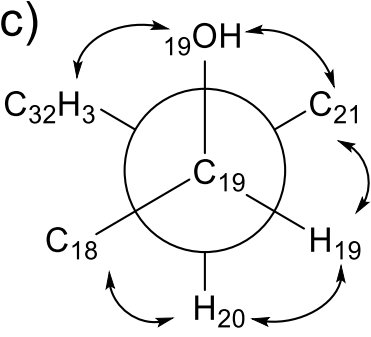

${ }^{3} J_{\mathrm{C} 32 \mathrm{H} 19}=8.0 \mathrm{~Hz}$

${ }^{3} J_{\mathrm{C} 21 \mathrm{H} 19}=2.1 \mathrm{~Hz}$

${ }^{3} J_{\mathrm{C} 18 \mathrm{H} 20}=4.3 \mathrm{~Hz}$ 
Figure S22. Predicted structure of modules 5-7 by TransATor.

\section{Trans-AT PKS derived polyketide prediction results}

The annotation of the different trans-AT PKS KS clades on the submitted sequences produces the following structure:

The annotation for each sequence submitted can be seen in the sections below.

\section{Dumulmycin}

Zoom - Start:1, End:1991

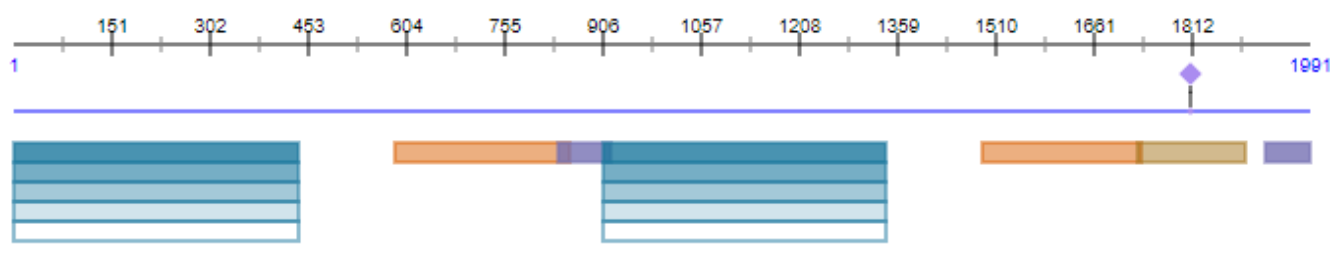

Dumulmycin 


\section{References}

[1] Hu, D.; Chen, Y.; Sun, C.; Jin, T.; Fan, G.; Liao, Q.; Mok, K. M.; Lee, M.-Y. S. Sci. Rep. 2018, 8, 14271.

[2] Mu. Y.; Yu, X.; Zheng, Z.; Liu, W.; Li, G.; Liu, J.; Jiang, Y.; Han, L.; Huang, X. Mag. Reson. Chem. 2019, 57, 1150-1157.

[3] Halgren, T. A. J. Comput. Chem. 1996, 17, 490-519.

[4] Hwang, S.; Shin, D.; Kim, T. H.; An, J. S.; Jo, S.-I.; Jang, J.; Hong, S.; Shin, J.; Oh, D.-C. Org. Lett. 2020, 22, 3855-3859.

[5] Rhoads, A.; Au, K. F. Genomics Proteomics Bioinformatics 2015, 13, 278-289.

[6] Chin, C. S.; Alexander, D. H.; Marks, P.; Klammer, A. A.; Drake, J.; Heiner, C.; Clum, A.;

Copeland, A.; Huddleston, J.; Eichler, E. E.; Turner, S.W.; Korlach, J. Nat. Methods 2013, 10, 563 569.

[7] Blin, K.; Shaw, S.; Steinke, K.; Villebro, R.; Ziemert, N.; Lee, S. Y.; Medema, M. H.; Weber, T. Nucleic Acids Res. 2019, 47, W81-W87.

[8] Shin, Y.-H.; Ban, Y. H.; Kim, T. H.; Bae, E. S.; Shin, J.; Lee, S. K.; Jang, J.; Yoon, Y. J.; Oh, D.-C. J. Nat. Prod. 2021, 84, 239-246. 